\title{
Development of the nervous system in Phoronopsis harmeri (Lophotrochozoa, Phoronida) reveals both deuterostome- and trochozoan-like features
}

Elena Temereva ${ }^{1}$ and Andreas Wanninger ${ }^{2^{*}}$

\begin{abstract}
Background: Inferences concerning the evolution of invertebrate nervous systems are often hampered by the lack of a solid data base for little known but phylogenetically crucial taxa. In order to contribute to the discussion concerning the ancestral neural pattern of the Lophotrochozoa (a major clade that includes a number of phyla that exhibit a ciliated larva in their life cycle), we investigated neurogenesis in Phoronopsis harmeri, a member of the poorly studied Phoronida, by using antibody staining against serotonin and FMRFamide in combination with confocal microscopy and 3D reconstruction software.

Results: The larva of Phoronopsis harmeri exhibits a highly complex nervous system, including an apical organ that consists of four different neural cell types, such as numerous serotonin-like immunoreactive flask-shaped cells. In addition, serotonin- and FMRFamide-like immunoreactive bi- or multipolar perikarya that give rise to a tentacular neurite bundle which innervates the postoral ciliated band are found. The preoral ciliated band is innervated by marginal serotonin-like as well as FMRFamide-like immunoreactive neurite bundles. The telotroch is innervated by two neurite bundles. The oral field is the most densely innervated area and contains ventral and ventro-lateral neurite bundles as well as several groups of perikarya. The digestive system is innervated by both serotonin- and FMRFamide-like immunoreactive neurites and perikarya. Importantly, older larvae of P. harmeri show a paired ventral neurite bundle with serial commissures and perikarya.
\end{abstract}

Conclusions: Serotonin-like flask-shaped cells such as the ones described herein for Phoronopsis harmeri are found in the majority of lophotrochozoan larvae and therefore most likely belong to the ground pattern of the last common lophotrochozoan ancestor. The finding of a transitory paired ventral neurite bundle with serially repeated commissures that disappears during metamorphosis suggests that such a structure was part of the "ur-phoronid" nervous system, but was lost in the adult stage, probably due to its acquired sessile benthic lifestyle.

Keywords: Neurogenesis, Evolution, Phylogeny, Ventral nerve cord, Last common lophotrochozoan ancestor

\footnotetext{
* Correspondence: andreas.wanninger@univie.ac.at

${ }^{2}$ Dept. of Integrative Zoology, University of Vienna, Althanstr 14, 1090,

Vienna, Austria

Full list of author information is available at the end of the article
} 


\section{Background}

Although the exact phylogenetic position of Phoronida is still a matter of ongoing debate (and in some recent studies even their monophyly is questioned, e.g., $[1,2]$ ), all recent molecular analyses agree in their inclusion within the protostome superclade Lophotrochozoa [3-5]. Mainly based on a proposed homologous feeding organ, the lophophore, Phoronida has been traditionally aligned with Ectoprocta and Brachiopoda to form the monophyletic Lophophorata [6,7]. This view is supported by a shared radial type of cleavage [8] (although some unpublished observations claim that spiral cleavage may be present in some phoronids), but otherwise there is little morphological support for such an assemblage, mainly due to the high disparity of the adult bodyplans of these phyla. The same is true for the proposed lophophoratespiralian alignment, where autapomorphies are hard to come by, one of them may be the occurrence of a larval apical organ with serotonin-like immunoreactive flaskshape cells [9]. On the other hand, lophophorates share some embryological features with the seemingly distantly related deuterostomes, such as the above-mentioned radial cleavage $[8,10]$, the (sometimes questioned) three coelomic compartments [11], and an upstream ciliary filter feeding system $[12,13]$.

The nervous system is often considered highly conserved between major animal taxa and is therefore often used for morphology-based phylogenetic inferences [14]. While an impressive amount of data on the development of the nervous system has recently become available for numerous lophotrochozoan subtaxa, phoronid neurogenesis is still comparatively little known, with most studies dealing with the description of the neuroanatomy of more or less mature larvae rather than with the development of the nervous system as such [15-21]. There are exceptions to the rule, however, but the few studies on phoronid neural development are restricted to one species belonging to the genus Phoronis and are not detailed enough to allow for answers concerning crucial issues such as the exact cellular composition and arrangement of the apical organ, thus rendering comparisons with other lophophorates, or even spiralians, difficult. Accordingly, a reconstruction of the neural anatomy of the larva of the last common lophophorate (and therefore lophotrochozoan) ancestor remains highly speculative. The unexpected recent finding of a paired ventral neurite bundle in the actinotroch larva of Phoronopsis harmeri [22] similar to most spiralians may provide evidence for such a neural system in the phoronid as well as lophotrochozoan groundplan. Such a scenario would imply, however, secondary loss of this paired ventral nervous system in adult phoronids (probably as a result of a sessile lifestyle), since they do not exhibit a comparable neural structure. In order to broaden the database on phoronid neurogenesis and larval neuroanatomy and to contribute to the discussion concerning the groundpattern of the phoronid and lophotrochozoan neural bauplan, we investigated the development of the serotoninlike and FMFRamide-like immunoreactive nervous system during larval development of Phoronopsis harmeri.

\section{Results}

\section{Description of major developmental stages}

The development of Phoronopsis harmeri was previously described in detail [10]. We briefly describe here the gross morphological characters of the crucial stages of larval development. The apical plate, which later includes the apical organ with an apical ciliary tuft, appears in the early gastrula (approximately $18 \mathrm{~h}$ post spawning (hps)), which has a flattened vegetal pole and a round blastopore (Figure 1A, B). The first immunoreactive cells differentiate only in the mid-gastrula stages (approximately $32 \mathrm{hps}$ ).

Mid-gastrula (approximately $30-37$ hps): this stage is $140 \mu \mathrm{m}$ long and $100 \mu \mathrm{m}$ wide. The archenteron is rounded (Figure 1D). The blastopore is flask-shaped with swollen anterior and narrow posterior portions (Figure 1C). At this stage, the anterior mesodermal precursor resembles a large mass of cells in front of and on both sides of the archenteron (Figure 1D).

Late gastrula I (approximately, 40-47 hps): this stage has an elongated archenteron with a cone-shaped posterior portion (Figure 1E). It represents the anlage of the future midgut. The blastopore closes and becomes tearshaped with a narrow posterior portion (Figure 1F). The volume of the blastocoel decreases in the posterior part of the embryo. Cells of the anterior coelomic precursor often form processes that pass to the apical plate, and the preoral coelom forms in the anterior part of the embryo (Figure 1G).

Late gastrula II (approximately 48-52 hps): the body shape of this stage differs from that of the previous stage in that the mouth becomes deeper and the precursor of the preoral lobe forms (Figure $1 \mathrm{H}$ ). The latter is an epidermal fold that is formed by two epidermal layers above the mouth. On the lateral and ventral sides of the posterior portion of the body, the postoral ciliated band, which is a belt of thick epithelium, appears. At this stage, the midgut contacts the surface of the epidermis of the posterior body part.

Preactinotrocha (approximately, 55-63 hps.): At this stage, the proctodaeum appears but the larva is still lecithotrophic (Figure 1I). The larva has a well-developed esophageal muscle, the preoral coelom, and the postoral ciliated band, which does not yet contain motionless latero-frontal cilia.

Young actinotrocha (approximately, 63-70 hps.): This stage has a well-developed preoral lobe (Figure 1J). 
The preoral lobe is the large anterior portion of the larva and has a large blastocoel, which is crossed by processes of mesodermal cells. The latero-frontal cilia on the tentacular ridge appear and the larva starts to feed.
On both sides of the anus, small epidermal invaginations arise, which form the protonephridial tubes.

5- to 6-day-old actinotrocha: The larva has large blastocoels in the hyposphere, a short trunk under the

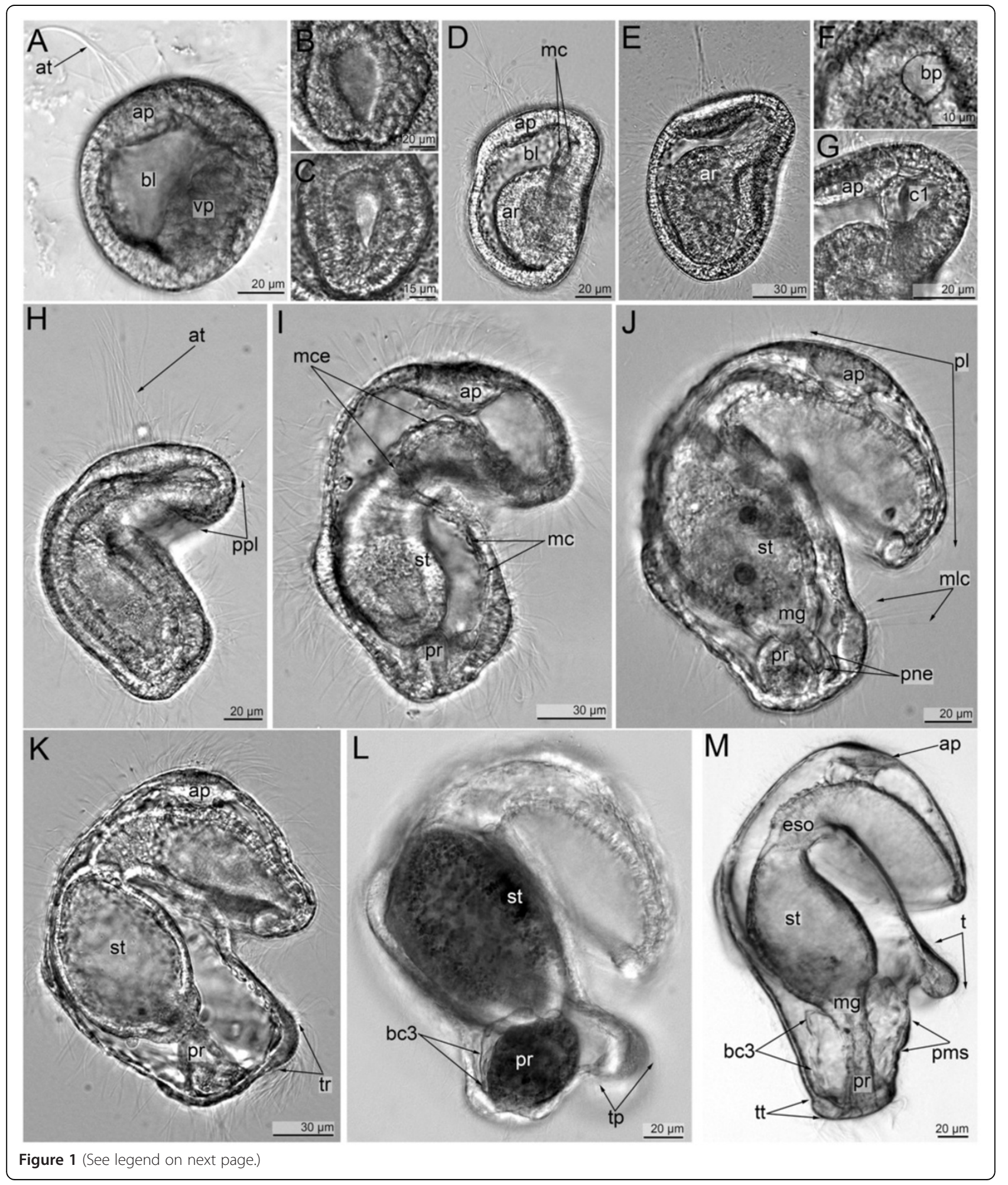




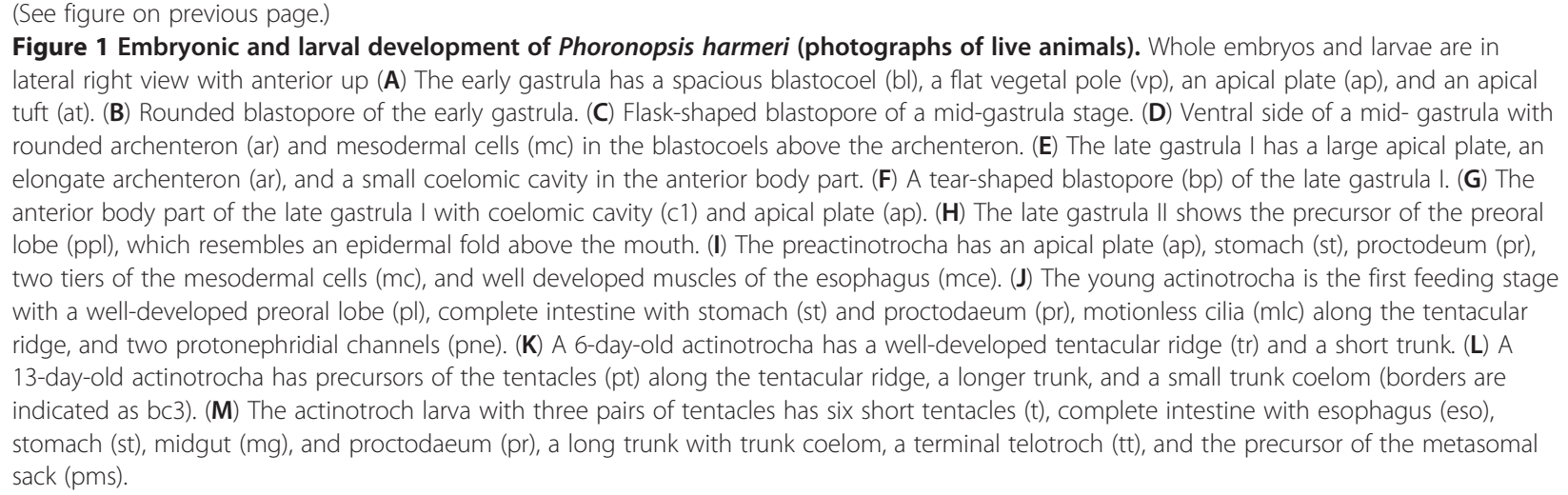

tentacular ridge, and well-developed two protonephridia with several terminal cells (Figure $1 \mathrm{~K}$ ).

13-day-old actinotrocha: Specimens feed, increase in size, and retain nutrients in the cells of the stomach and hindgut (Figure 1L). There are three pairs of protrusions along the tentacular ridge, the primordial tentacles.

Actinotrocha with three pairs of tentacles (approximately 24 days after spawning): The larva has a welldeveloped trunk with a terminal telotroch around the anus (Figure $1 \mathrm{M}$ ). The ventral pair of tentacles is the longest, and the dorso-lateral pair is the shortest. The trunk is occupied by a large trunk coelom. On the ventral body side under the tentacles, an area of thick epidermis appears which forms the primordium of the metasomal sac.

\section{Neurogenesis}

Although the apical tuft and the apical plate form in the early gastrula, perikarya do not differentiate and connect to the sensory cells of the apical plate until the mesodermal muscle cells appear, which is in the mid-gastrula stage.

\section{Serotonin-like immunoreactive nervous system}

During the mid-gastrula stage, the first perikarya differentiate in the epithelium of the apical plate (Figure 2A-C). Four serotonin-like immunoreactive flask-shaped perikarya usually differentiate simultaneously (Figure 2D, 3A, B). They are located at the anterior edge of the apical plate and have a thickened basal part and a narrow apical part (Figure 2C-insert 1, 3B). The apical part contacts the surface and bears the cilium. The basal part of each cell forms short processes that project towards the central part of the apical plate (Figure 2C, C-insert 1). Most somatic cells of the embryo have a tear-shaped nucleus with a wide basal part and a thin apical part (Figure 2C). This form of nucleus is also typical for serotonin-like immunoreactive perikarya (Figure 2C-insert 2).

In the late gastrula I (Figure 2E), the basal processes of serotonin-like immunoreactive perikarya form a neuropil in the center of the apical plate (Figure 2F). Nerve fibers occupy the basal portion of the apical plate and are in close contact with the mesodermal cells (Figure 2F). At this stage, the shape of perikarya does not change but the number increases with age and is seven or nine in the late gastrula II (Figure 2G). The arrangement of the perikarya forms a horseshoe-like pattern along the anterior edge of the apical plate. The apical portion of the cell becomes longer (Figure 2J). The neuropil becomes rounded and larger (Figure 2J). At this stage, and usually within the apical organ, there are two perikarya which are situated very closely adjacent to each other and form a cluster with two apical parts, two nuclei, and one process (Figures $2 \mathrm{H}, 3 \mathrm{C}$ ).

The number of perikarya in the apical organ increases and the preactinotrocha has 12 perikarya (Figures $2 \mathrm{~K}, \mathrm{~L}$, 3D, E). The apical organ also increases in size and the perikarya are arranged in a wide horseshoe-like pattern with a large neuropil in the center (Figure 3D, E).

In young actinotrochs (Figure 4A), the apical organ retains its previous organization and consists of 13-15 monopolar, monociliated flask-shaped cells (Figure 4B, C). At the same time, the shape of some perikarya starts to change (Figure 4D-F). The apical organ contains one or two perikarya, which have a thin area between the nucleus and the apical part of the cell (Figure 4E). This area becomes progressively thinner, whereas the basal part of the cell (the part with the nucleus) becomes wider (Figure 4E). Simultaneously, the basal part of the cell migrates to the basal portion of the apical plate, and the nucleus of the perikaryon is then located under the common row of nuclei (Figure 4G). Perikarya with thin median portions are best identified in three-dimensional reconstructions (Figure 3E). The bipolar or multipolar perikarya result from these processes. Later, these bipolar perikarya can be found within the perikarya of the apical organ (Figure 4H). The young actinotroch usually has two or three bipolar perikarya within the apical organ. They are located in front of the neuropil and on the dorsolateral side of the neuropil. The first serotonin-like 


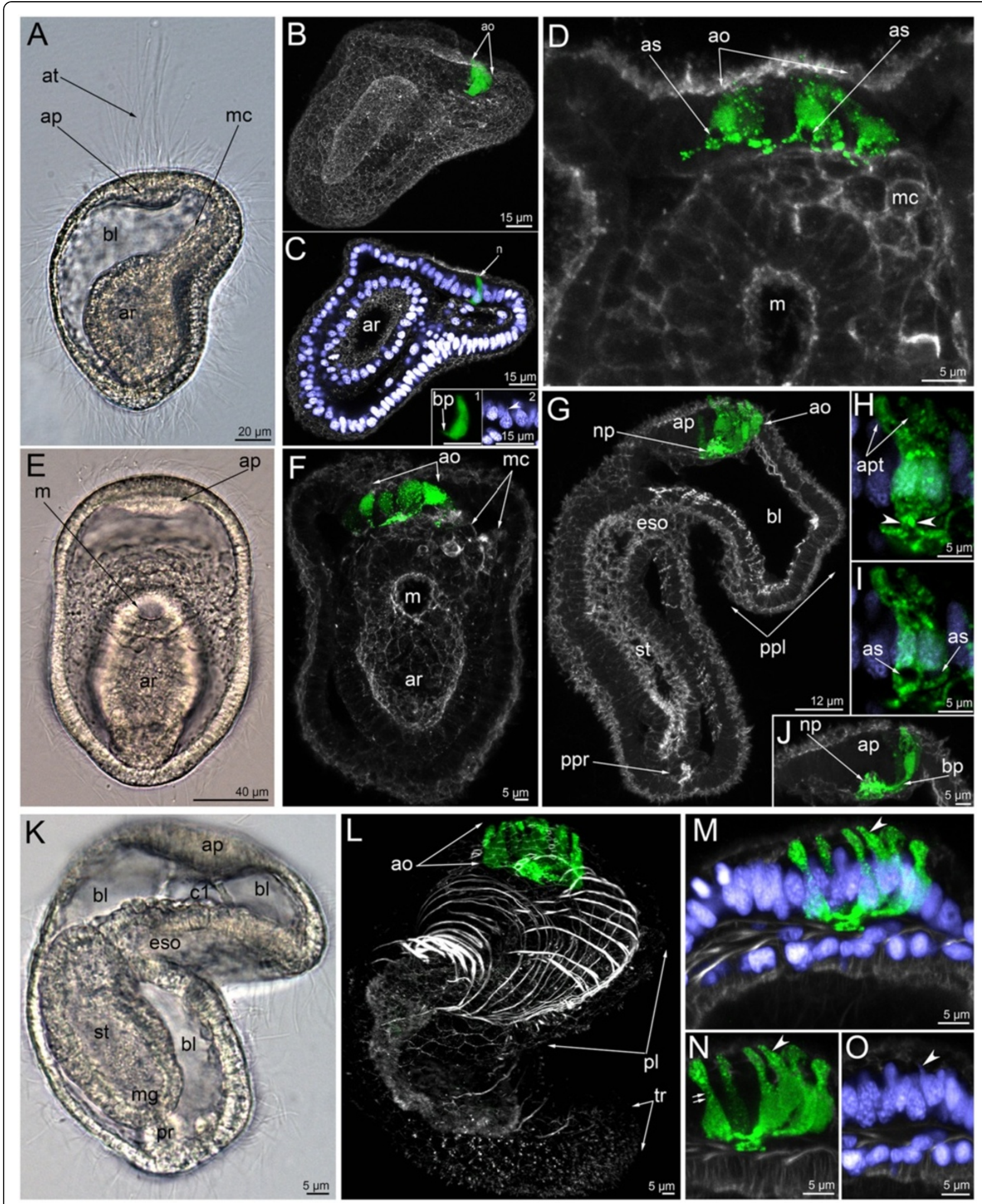

Figure $\mathbf{2}$ (See legend on next page.) 


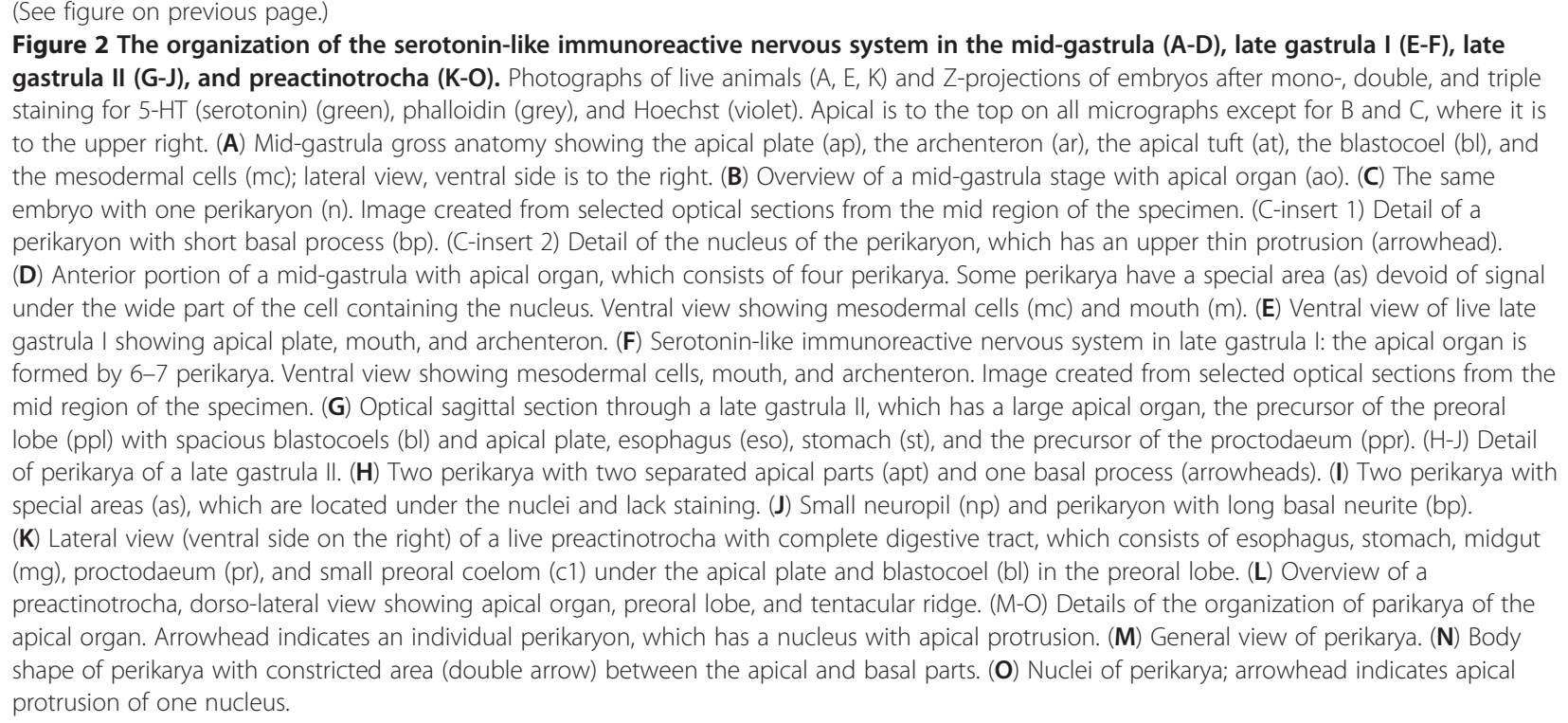

immunoreactive neurites appear in the young actinotroch (Figures 3F, 4I, 5A). The pair of dorso-lateral neurites originates from the neuropil and passes along the dorso-lateral sides of the preoral lobe to the dorsal ends of the postoral ciliated band (Figures 4I, 5A). Here, each nerve tract bifurcates into short branches with swollen ends (Figures 3F, 4J, 5A).

In the 5-day-old actinotroch (Figure 4K), additional serotonin-like immunoreactive neurites appear along the edge of the preoral lobe. They form two rows, which constitute the anterior and posterior marginal neurite bundles (Figure 4L). Each anterior marginal nerve passes along the marginal muscle of the preoral lobe and contains 4-5 bipolar serotonin-like immunoreactive perikarya. The posterior marginal neurite bundle is stained more intensely than the anterior marginal neurite bundle and connects with 12-15 large serotonin-like immunoreactive perikarya (Figure 4L). The anterior and posterior margin neurite bundles merge at the dorsal ends of the preoral lobe. Dorso-lateral neurite bundles emerging from the neuropil increase in diameter, pass along the tentacular ring, and form contact on the ventral side, forming the tentacular nerve ring (Figure 4L). The number of monopolar perikarya within the apical organ does not increase, but the shape of the perikarya does (Figure 4M). In the 5-day-old actinotroch, monopolar perikarya have a long basal process, which can reach $6 \mu \mathrm{m}$ in length. The basal part of the perikaryon is wide and rounded (Figure $4 \mathrm{~N}$ ) and the nucleus is located here. The apical part of the cell resembles a collar and stains intensely. A serotonin-like immunoreactive cell with one basal process, two rounded nuclei (basal and apical), a small apical part, and a cilium (Figure 4O, P) can be found among other perikarya. Within the apical organ, there are bipolar or multipolar perikarya, which are located among the fibers of the neuropil (Figure 4Q); these perikarya have a large and irregularly shaped nucleus and they always occupy the anterior and lateral edge of the neuropil (Figure 4Q). Two bipolar cells can usually be found near the apical organ (Figure 4M). These cells are associated with the dorso-lateral branches of the tentacular neurite bundle and are located on both sides of the apical organ. A round nucleus is located in the center of the perikaryon.

In the 6-day-old actinotroch larva (Figure 6A), the serotonin-like immunoreactive nervous system becomes more complex (Figures 3G-J, 5B, 6). All previous elements are retained and new elements appear (Figure 6B). At this stage, typically, the apical organ contains 12-15 monopolar serotonin-like immunoreactive perikarya, but up to 25 monopolar perikarya were found within the apical organ in some larvae (Figure 6E). The neuropil of the apical organ becomes more elaborate and can be recognized even in live larvae, where it resembles a transparent bubble under the apical plate epithelium (Figure 6D). The basal processes of the monopolar perikarya branch before they form contact with the neuropil and form a neural meshwork (Figure 6F). Bipolar or multipolar perikarya occur in the neuropil. The posterior and anterior marginal neurite bundles of the preoral lobe retain several bipolar perikarya. These neurites can not be recognized in subsequent stages (Figure 6B, E). Approximately 14 perikarya are distributed along the anterior marginal neurite bundles and five of them are concentrated in its median portion (Figure 6G). The dorso-lateral neurite bundle of the tentacular ring divides into two near the neuropil (Figure 6J). The branches of one neurite bundle fuse on the dorsal side. Three- 


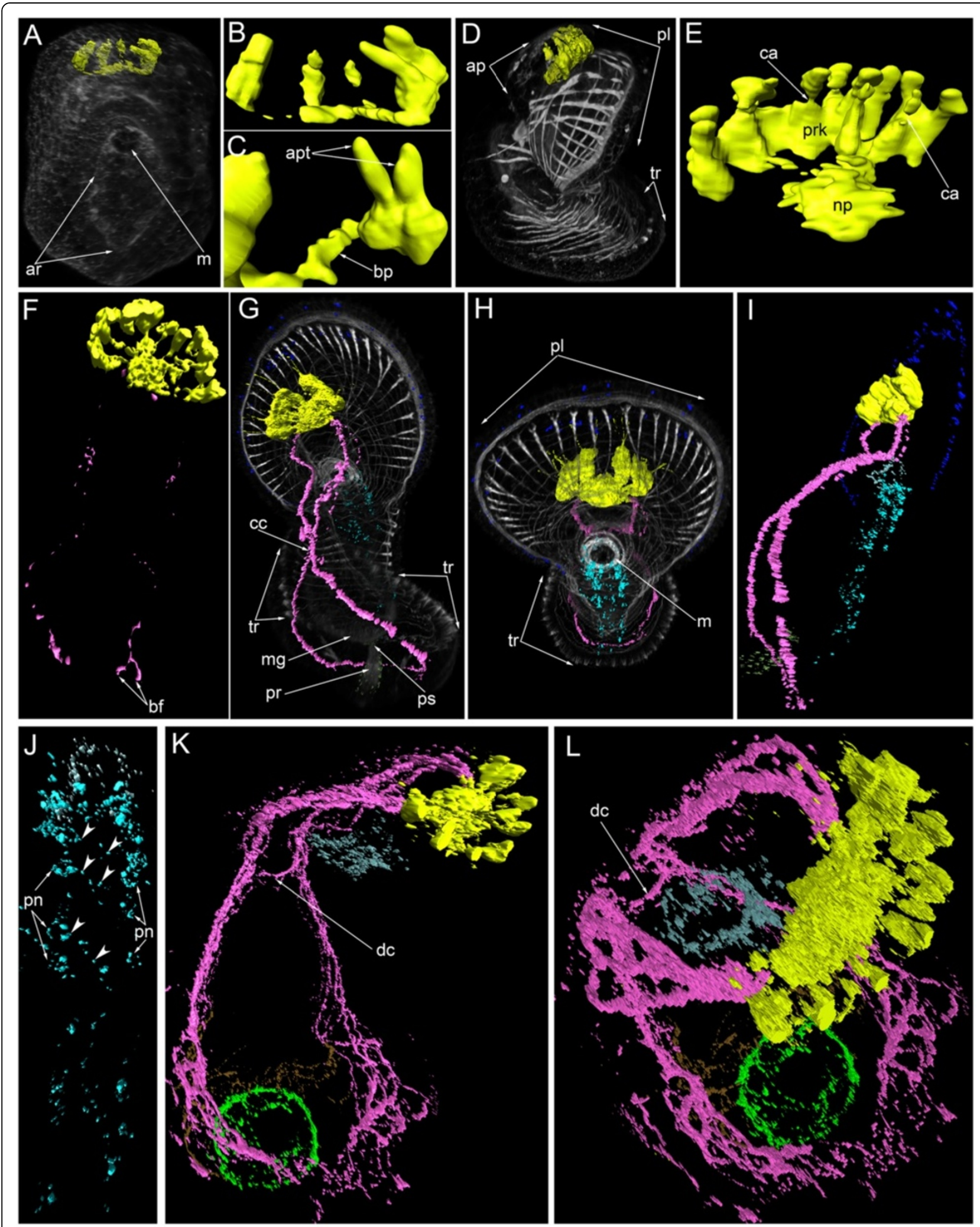

Figure 3 (See legend on next page.) 


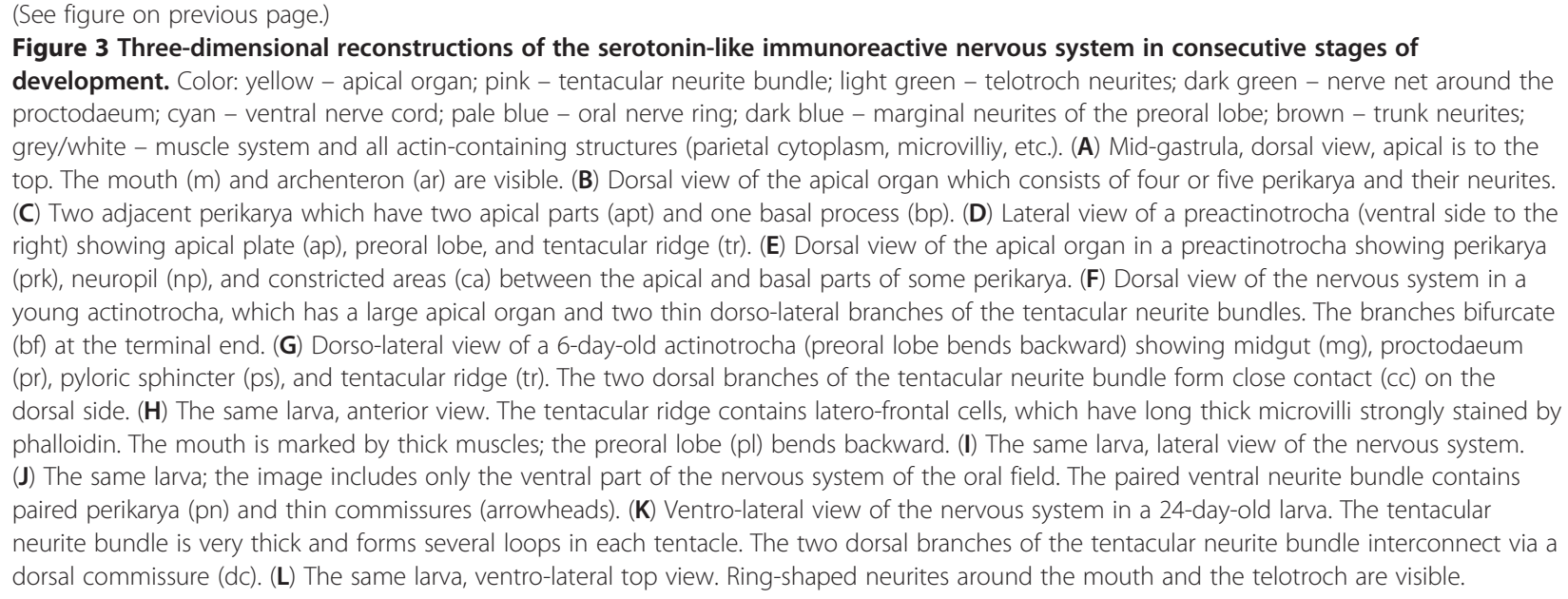

dimensional reconstruction reveals that the tentacular neurite bundle runs along the lower edge of the tentacular ridge. As in the previous stage, two bipolar perikarya are associated with the two dorso-lateral neurite bundles. These perikarya are located on both sides of the neuropil (Figure 6E, J). In the 6-day-old larva, an oral nerve ring appears (Figure 6H, I, K). It is composed of thin circular neurites, which also extend along the esophagus. The oral nerve ring does not contact the apical organ. In some larvae, serotonin-like immunoreactive perikarya occur under the oral ring and on its left and right sides (Figure 6H). Larvae of this stage also have serotonin-like immunoreactive processes around the proctodeum and the pyloric sphincter (Figure 6C, J). Interestingly, immunofluorescence can be observed in the apical portion of the epithelium of the proctodaeum (Figure 6C). A paired serotonin-like immunoreactive neurite bundle appears in the epithelium of the oral field, between the oral nerve ring and the tentacular neurite bundle (Figure 6B, K, L). It consists of two longitudinal neurite bundles and commissures, which interconnect the perikarya of the two neurite bundles. Each longitudinal neurite bundle includes thin neurites and six perikarya and contacts the oral nerve ring via paired perikarya, which are situated in close proximity to the oral nerve ring (Figure 5B,6K, L). This serotonin-like immunoreactive paired ventral neurite bundle was previously described [22], and here we provide micrographs of a different larval specimen (Figure 6K-M). 3D reconstruction of another larva reveals the presence of repetitive perikarya and thin commissures between them (Figure 3H, J).

In 13-day-old actinotrochs, the general organization of the nervous system changes (Figure 7A-C). The anterior and posterior marginal neurite bundles become very weak, and serotonin-like immunoreactive perikarya along them are not evident (Figure 7C). The paired ventral neurite bundle can not be recognized. The tentacular neurite bundle becomes more complex. Its dorso-lateral parts bifurcate and each branch forms two additional branches, which fuse on the dorsal side (Figure 7C). The ventral portion of the tentacular neurite bundle also changes such that many thin small loops extend along its edge (Figure 7C). The apical organ contains numerous bipolar or multipolar perikarya (Figure 7D). The number of monopolar perikarya does not increase substantially. The basal processes of the monopolar perikarya bear several varicosities (Figure 7E). When the tentacles become more pronounced, branches of the tentacular neurite bundle extend into each tentacle (Figure 7F). A neurite bundle runs along the abfrontal side of each tentacle (Figure 7G). The apical plate has a complex structure and contains sensory cells and perikarya (Figure 7H). Sensory cells can be recognized by the presence of long microvilli on the apical surface; these microvilli are strongly stained by phalloidin (Figure 7H, I). Sensory cells form an external row on the periphery of the apical plate and form two rows in the center. Double staining with phalloidin and against serotonin reveals the position of serotonin-like immunoreactive perikarya and sensory cells (Figure 7I). The former are situated on the periphery of the apical plate between the sensory cells. Thus, serotonin-like immunoreactive perikarya are distant from the center of the apical plate where the neuropil is situated. For this reason, each monopolar perikaryon forms a long $(16 \mu \mathrm{m})$ basal process (Figure 7J). Large varicosities occur along the process. Bipolar or multipolar perikarya form a layer under the neuropil, along its anterior edge (Figure 7K, L). This layer is composed of 8-10 perikarya. The most dorsal multipolar perikarya give rise to the dorso-lateral branches of the tentacular neurite bundle (Figure 7L).

In 24-day-old actinotrochs the general organization of the serotonin-like immunoreactive nervous system 


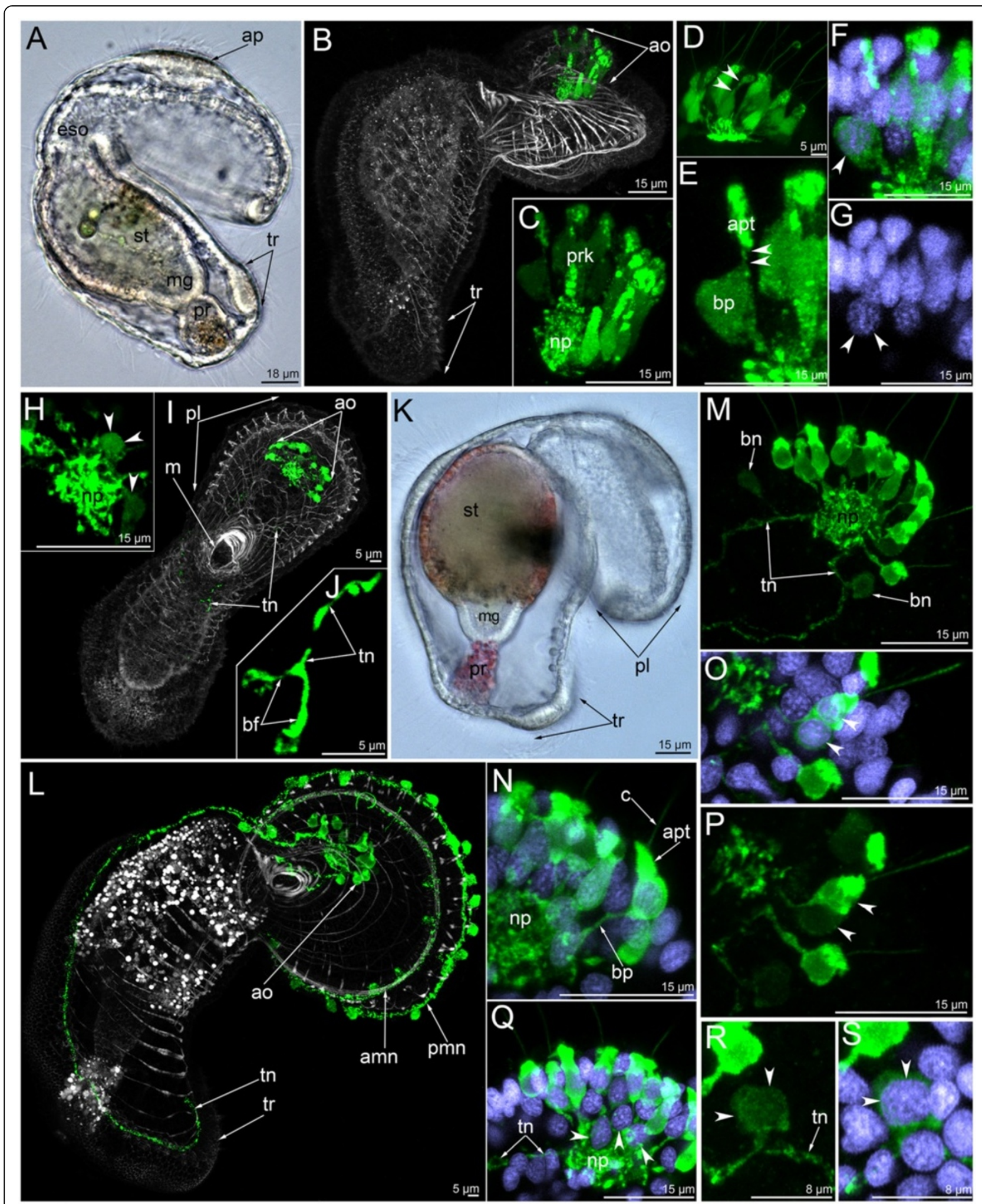

Figure 4 (See legend on next page.) 


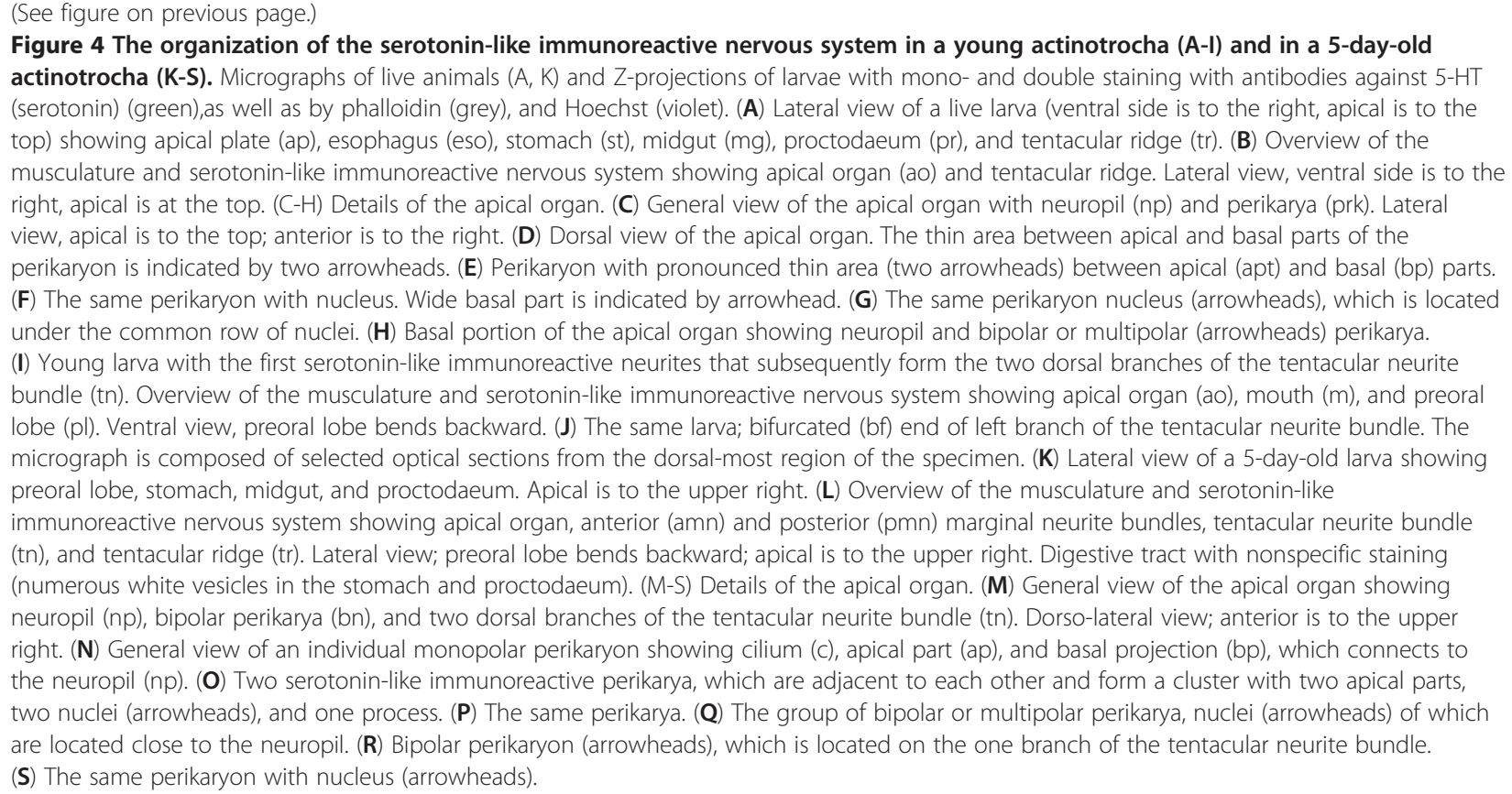

changes (Figure 5C, 8). At this stage, the apical organ and the tentacular neurite bundle are the main elements of the nervous system (Figure 8B, D). The apical organ is composed of 20-25 monopolar perikarya and 12-15 bipolar or multipolar perikarya (Figure 8C, E). Each monopolar perikaryon has a flask-like shape with a wide basal part and a narrow apical part (Figure 8F). The basal part of the cell forms a single process, which usually arises from the terminal basal part of the perikaryon. In some perikarya, however, it projects from the central part of the perikaryon (Figure 8G). The processes of all monopolar perikarya extend to the center of the apical organ and contribute to the apical neuropil (Figure 8K). Under this neuropil, bipolar or multipolar perikarya and their processes are situated (Figure 8J, K). They are arranged in two groups, left and right, and each group consists of 4-5 spherical perikarya that are 5-6 $\mu \mathrm{m}$ in diameter (Figure 8F). Interestingly, in some larvae the left dorso-lateral group of multipolar perikarya form a large mass, which rises above the neuropil (Figure $8 \mathrm{C}$ ). The multipolar perikarya are located near the anterior and lateral edge of the neuropil, whereas their processes occupy the dorsal portion. The serotonin-like immunoreactive part of the neuropil is ovoid and 16-17 $\mu \mathrm{m}$ long and $8-9 \mu \mathrm{m}$ wide.

The 24-day-old actinotroch has a weak marginal neurite bundle with several perikarya (Figure 5C) and a prominent median neurite bundle, which extends from the apical organ to the edge of the preoral lobe along its median line (Figure 8E, H, J, K). The median neurite bundle arises from the left group of multipolar perikarya
(Figure 8F, J). In some larvae, a group of weakly stained perikarya is found in the center of the median neurite bundle (Figure $8 \mathrm{H}$ ). This group consists of three small perikarya that contribute to the frontal organ. In some larvae, there is only one perikaryon instead of three (Figure 8B). Two dorso-lateral branches of the tentacular neurite bundle arise from the dorso-lateral parts of the neuropil where the multipolar perikarya are situated (Figure 8J, K). Near the apical organ, each dorso-lateral neurite bundle branches into several neurite bundles, which fuse on the dorsal side (Figure $8 \mathrm{~B}, \mathrm{E}$ ). Here, the dorso-lateral neurite bundles are connected to each other via a dorsal commissure (Figure $8 \mathrm{~B}, \mathrm{I}$ ). Along the whole length, the tentacular neurite bundle is formed by 7-10 neurites (Figure 8I). The tentacular neurite bundle runs under the tentacular ridge and forms a loop along the abfrontal side of each tentacle. The oral nerve ring is composed of thin circular neurites and several perikarya, which usually stain weakly (Figure $8 \mathrm{~B}$ ). These perikarya are located in the oral field epithelium, under the mouth. The oral nerve ring does not contact the tentacular neurite bundle or the apical organ, as stated previously [23]. Thin neurites form a cylinder, which matches the shape of the esophagus (Figures $3 \mathrm{~K}, 8 \mathrm{~B}$ ). In the 24-dayold larva, the trunk and the telotroch have formed (Figures 3L, 8B). The telotroch is innervated by two serotonin-like immunoreactive neurite bundles: the inner and the external one. They form two circles in the posterior end of the body (Figure 3L). Thin nervous fibers pass along the lateral and dorsal sides of the larval trunk (Figure 3K). 


\section{FMRFamide-like immunoreactive nervous system}

The earliest signal of the neuropeptide FMRFamide is found in the late gastrula and is located in the apical plate (Figures 9A, 10A). Cell processes are labeled at this stage, but no cell bodies were found (Figure 9B). Labeled cell processes form a neuropil in the center of the basal portion of the apical plate (Figure 9B). Mesodermal cells forming the protocoel lining contact the neurites of the

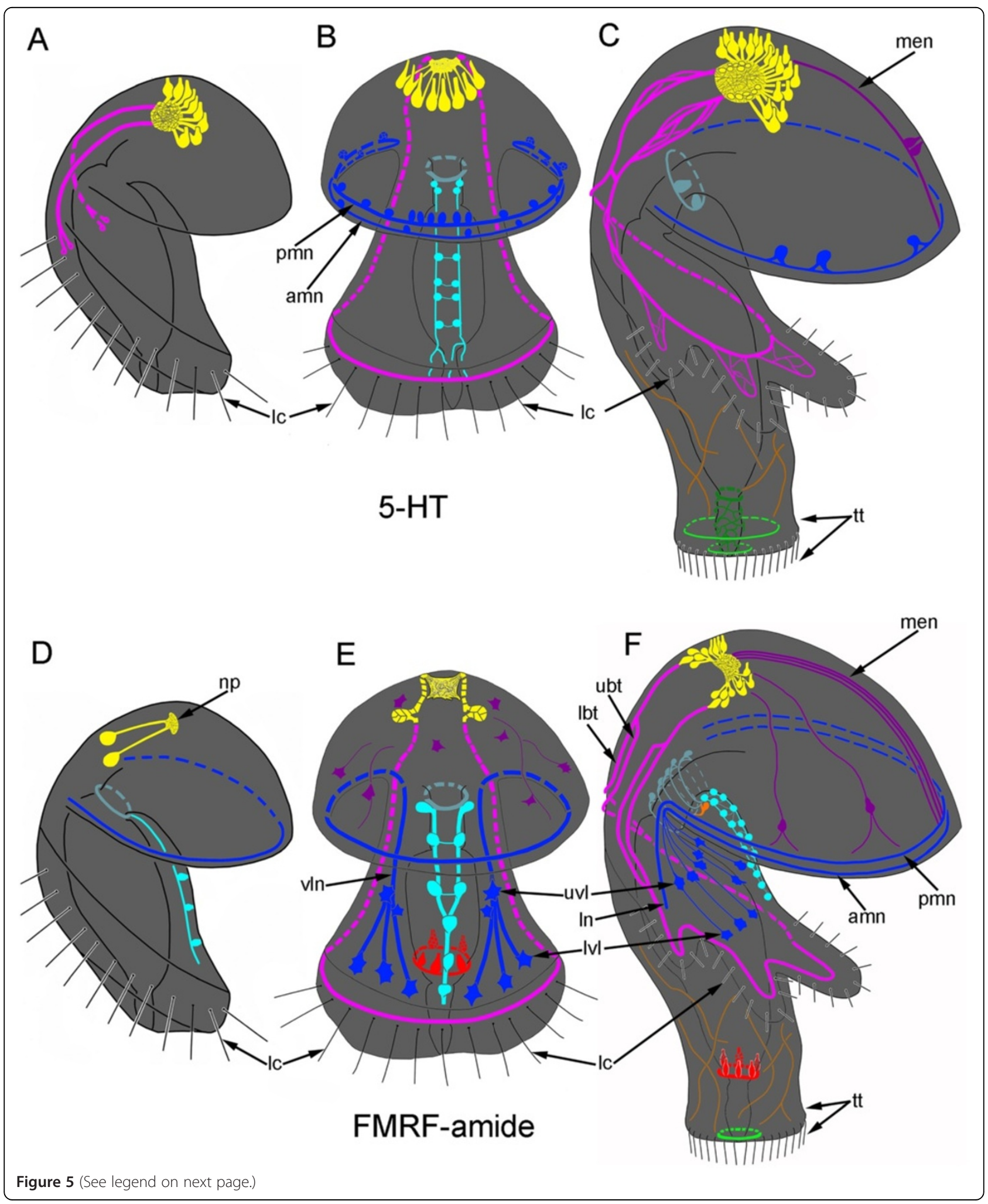


FMRFamide-immunoreactive neuropil (Figure 10B). Threedimensional reconstruction reveals that the neuropil is shaped like a horseshoe with two dorso-lateral branches (Figure 10A).

In the preactinotroch, the thin and interrupted FMRFamide-immunoreactive neurites appear along the edge of the preoral lobe (Figure 9C). Interestingly, the first FMRFamide reactive neurite runs along the edge of the preoral lobe, whereas the serotonin-like immunoreactive neurite extends from the apical organ to the tentacular ridge.

The first perikarya with FMRFamide-like immunoreactivity occur in the young actinotroch. Perikarya are situated on the dorso-lateral side of the preoral lobe behind the neuropil (Figures 5D, 9D, 10C). Usually, two or three perikarya appear simultaneously. These are large bipolar cells, which connect to the neuropil via thin neurites (Figure 9D). In young actinotrochs, several thin neurites originate around the mouth and along the medio-ventral line of the oral field (Figure 9D). These neurites are very weak (Figure 10C).

After several hours, new FMRFamide-immunoreactive elements appear in young actinotrochs (Figure 9E, F). These are the perikarya of the oral field epidermis, perikarya in the midgut, and radial neurites in the preoral lobe (Figures 9E-K, 10D). In young actinotroch larvae, the apical organ consists of bipolar and monopolar perikarya. The latter is column-shaped with wide apical and basal parts (Figure 9G). The basal part contains the nucleus; the apical part is always brightly stained. The basal part of the perikaryon forms a process that passes into the neuropil. Bipolar perikarya are located distant from the neuropil and connect to it via long anterior processes (Figure 9I). The posterior process runs along the dorso-lateral side of the body and forms the primary tentacular neurite bundle. At this stage, the paired ventral neurite bundle contains six bipolar perikarya, which contact each other via thin longitudinal neurites. These bipolar perikarya form the longitudinal neurite bundles which pass from the oral ring to the tentacular ridge (Figure 9H). Second, two groups of latero-ventral perikarya, each consisting of two or three perikarya (the lower ventro-lateral perikarya), are located near the tentacular ridge (Figure 9E). Third, two large perikarya arise on the ventro-lateral side near the site of contact between the preoral lobe and the hyposphere (the upper ventro-lateral perikarya) (Figure 9F, J). These perikarya connect to the marginal neurite bundle via the thin precursors of the ventro-lateral neurites (which is a part of the marginal neurite bundle and which continues into the oral field) (Figure 9J). Perikarya in the midgut are located near the pyloric sphincter; they are bipolar and triangular with a wide basal part that forms two processes that extend around the midgut (Figure 9K). Radial neurites of the preoral lobe are concentrated along its midline and run along the radial muscles (Figure 10D). At this stage, two to five radial neurites with median perikarya can be detected in the preoral lobe.

Five-day-old larvae contain all the neural elements observed in younger larvae (Figure 11F). The ventral neurite bundles, two large upper ventro-lateral perikarya, and two groups of lower ventro-lateral perikarya innervate the epidermis of the oral field (Figure 11B). The apical organ becomes more complex. The number of monopolar perikarya increases, but their shape does not change (Figure 11C). The number of bipolar perikarya also increases (Figure 11D). In addition to the two main (first) perikarya, two lateral groups of bipolar perikarya develop. These perikarya stain weakly; they form two lateral groups which connect to the neuropil via a prominent neurite bundle (Figure 11D). The main perikarya stain brightly and give rise to the tentacular neurite bundle. The entire tentacular neurite bundle appears in the 5-day-old actinotroch (Figure 11A). In some larvae, the tentacular neurite bundle bifurcates into two branches, one below and one above the tentacular ridge (Figure 11E).

In 6-day-old larvae, new perikarya appear adjacent to the paired ventral neurite bundle and in the epidermis of the preoral lobe (Figures 5E, 10E, 11F). In the latter case, most of the perikarya form two main neurites: one passes into the neuropil and the other connects to the marginal neurite bundle (Figure 11G). In some cases, the perikarya of the preoral lobe form more than two neurites, which spread into the preoral lobe epithelium (Figure 11G). The perikarya of the ventral neurite bundles form two longitudinal rows, which contact each 


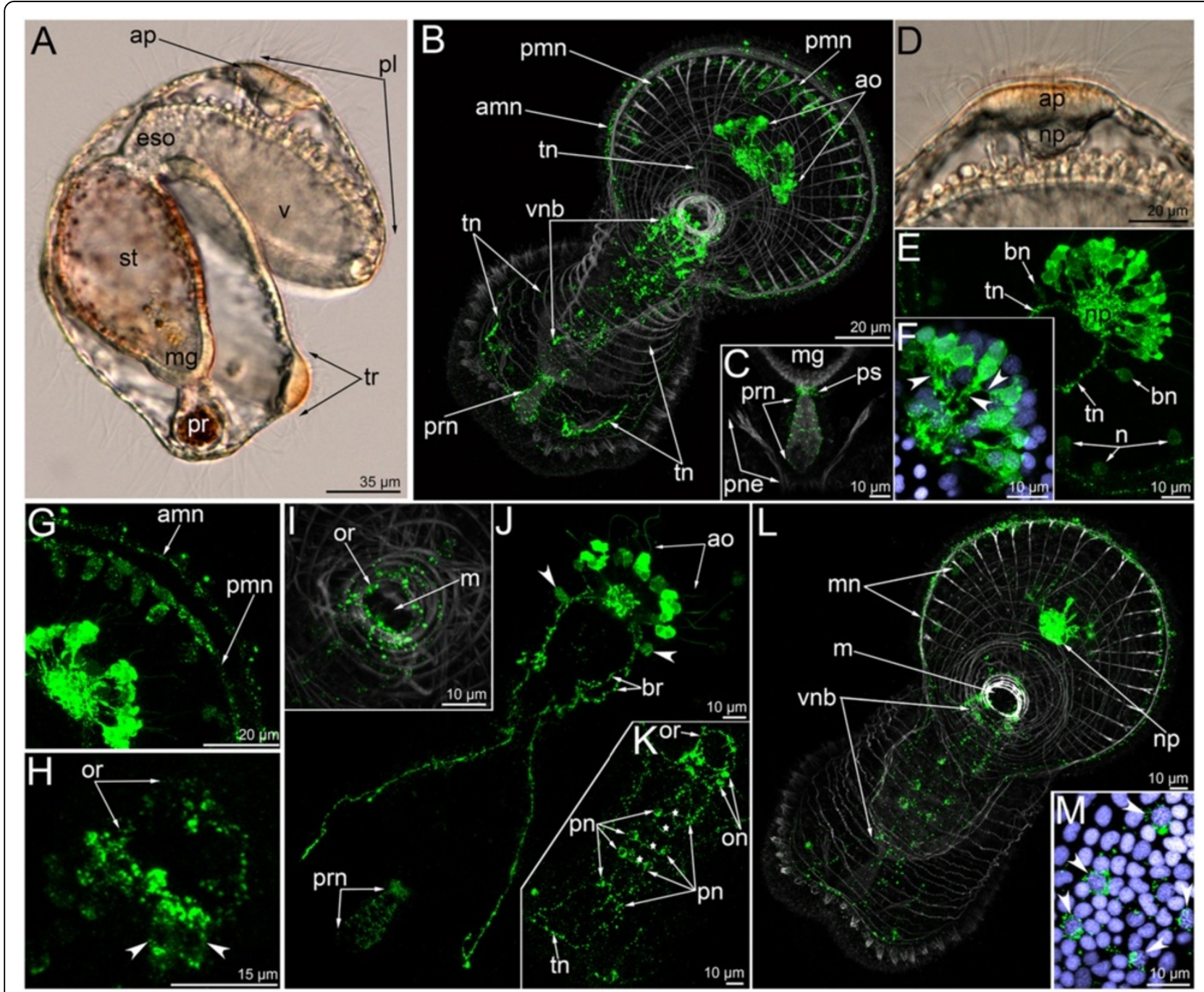

Figure 6 The organization of the serotonin-like immunoreactive nervous system in a 6-day-old larva. Micrographs of live animals (A) and Z-projections of larvae after mono- and double staining with antibodies against serotonin (green), as well as with phalloidin (grey), and Hoechst (violet). Apical is to the upper right on all micrographs except $A, C$, and D, where apical is to the top. (A) Lateral view with ventral to the right. Larva with apical plate (ap), preoral lobe (pl), vestibulum (v), esophagus (eso), stomach (st), midgut (mg), proctodaeum (pr), and tentacular ridge (tr). (B) Overview of the musculature and serotonin-like immunoreactive nervous system showing apical organ (ao), anterior marginal neurite bundle (amn), posterior marginal neurite bundle (pmn), tentacular neurite bundle (tn), and ventral neurite bundles (vnb). Ventral view; preoral lobe bends backward. (C) Posterior body part. The micrograph comprises selected optical sections from the mid body region of the specimen and shows the nerve net around the proctodaeum (prn) and the pyloric sphincter (ps), midgut (mg), and protonephridia. (D) Lateral view of the apical plate (ap) and large neuropile (np) underneath. The anterior pole of the preoral lobe is to the right. (E) Top view of the apical organ with dorsal neuropil (np), dorso-lateral branches of the tentacular neurite bundle (tn), and bipolar perikarya (bn). Some portions of the marginal neurites with perikarya $(\mathrm{n})$ are visible. (F) Details of the apical organ, anastomosing neurites are indicated by arrowheads. (G) Anterior portion of the edge of the preoral lobe with anterior (amn) and posterior (pmn) marginal neurite bundles with a group of perikarya associated with the latter. (H) Oral nerve ring with ventro-lateral, weakly stained perikarya (arrowheads); top view. (I) Innervation (oral nerve ring - or) and musculature of the mouth (m); ventral view. (J) Dorsal portion of the tentacular neurite bundle (tn) with two branches (br) of the right stem. apical organ (ao), bipolar perikarya (arrowheads), and nerve net of the proctodaeum (prn). (K) Oral field with the ventral neurite bundles, which pass from the oral ring (or) with oral perikarya (on) to the tentacular neurite bundle (tn), containing several paired perikarya (pn) and commissures (asterisks). The micrograph is composed of the most ventral optical sections only. (L) The image comprises only the four most ventral optical sections of the serotonin labeling and all sections of the muscle staining. Ventral view of a larva showing the marginal neurites $(\mathrm{mn})$ of the preoral lobe, the neuropil (np) of the apical organ, the mouth (m), and the ventral neurite bundles (vnb). (M) Some paired perikarya of the ventral neurite bundles with nuclei (arrowheads).

other via thin commissures (Figure 11F, $\mathrm{H}$ ). There are at least two commissures between the paired perikarya of the two longitudinal rows (Figures 10G, 11F, H). A new and large perikaryon appears near the mouth, in the epidermis of the oral field (Figure 10F). At this stage, the upper ventro-lateral perikarya form thin longitudinal 
ventro-lateral neurites, which contact the lower ventrolateral perikarya (Figures 10F, 11F).

In 13-day-old larvae, the number of upper ventrolateral perikarya increases to three or four (Figure 12A). Accordingly, the number of thin longitudinal neurites and the number of lower ventro-lateral perikarya also increases. At this stage, the connection is evident between the marginal neurite bundles of the preoral lobe, the upper ventro-lateral perikarya, the ventro-lateral longitudinal neurites, and the lower ventro-lateral perikarya

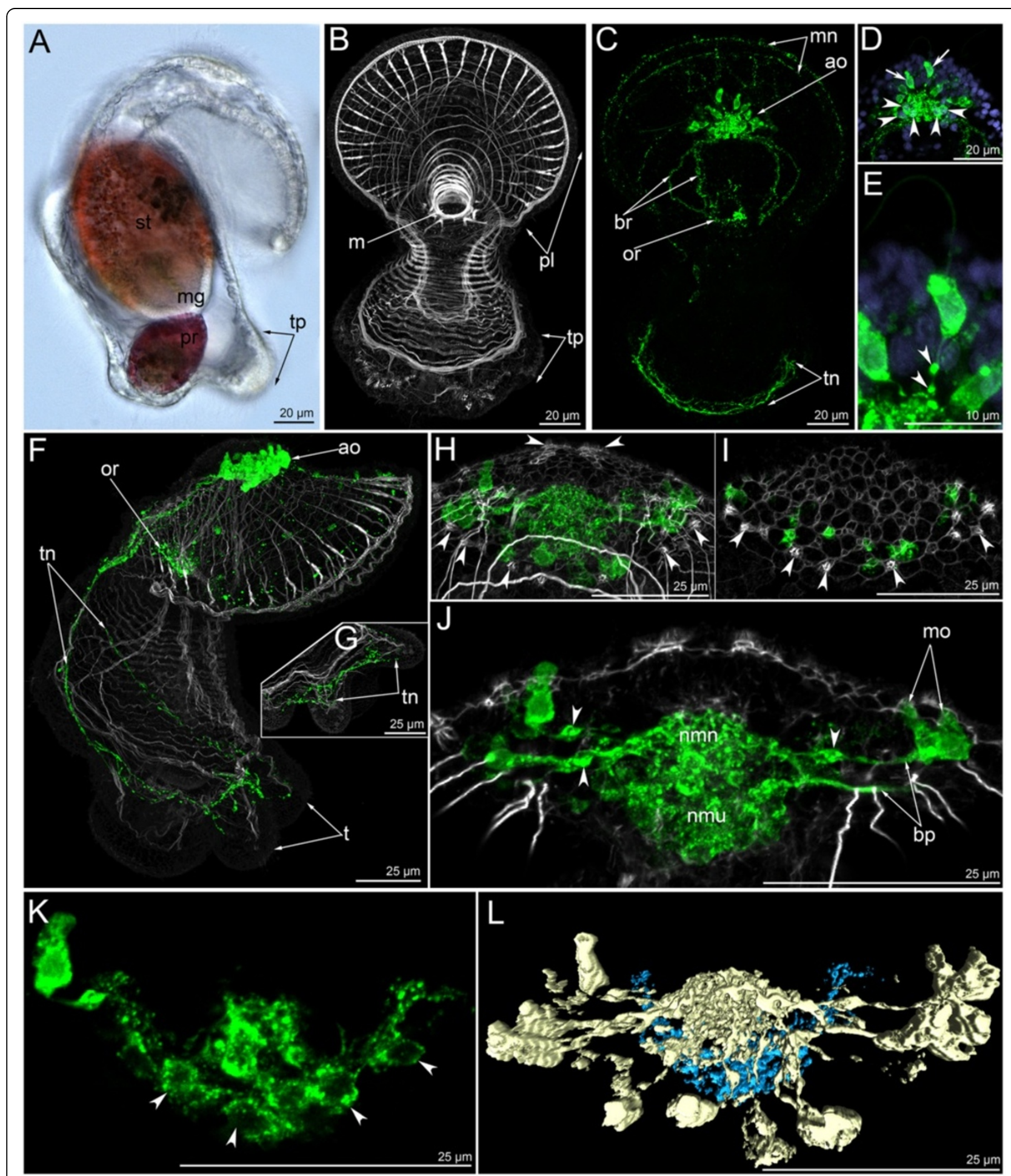

Figure 7 (See legend on next page.) 


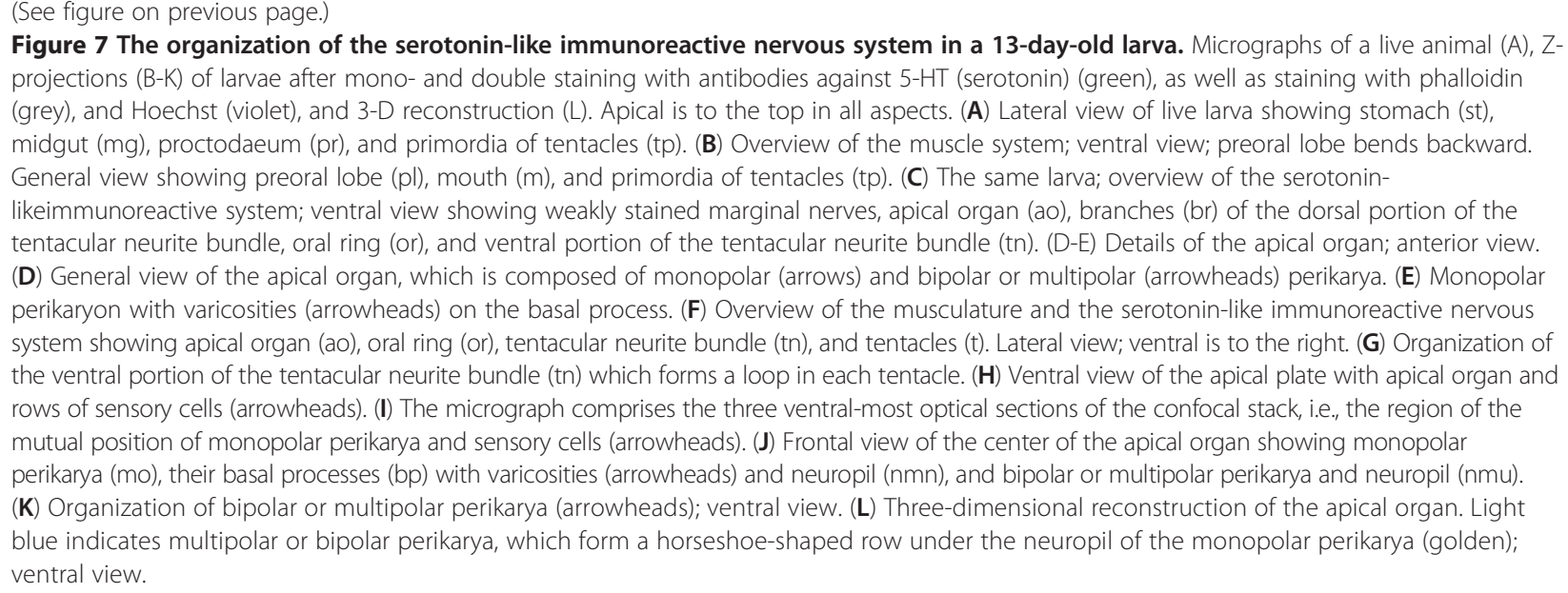

(Figure 12A). 13-day-old larvae have a well-developed nerve net around the mouth that is connected to the paired ventral neurite bundles on its lateral side (Figure 12A). The ventral neurite bundles comprise seven or eight paired perikarya. The paired perikarya lie very close to each other, and the commissures cannot be recognized (Figure 12A). Larvae at this stage have primordial tentacles, and the tentacular neurite bundle forms loops into each primordium. A 13-day-old larva has a short trunk and the telotroch appears around the anus. Monopolar and bipolar or multipolar perikarya of the apical organ form two lateral clusters (Figure 12A-insert). Monopolar perikarya occupy the ventro-lateral epidermis of the apical plate, on the both sides of the neuropil. Bipolar or multipolar perikarya are located in the dorso-lateral epidermis of the preoral lobe. These perikarya form a compact group with three or five perikarya, which produce dorsal neurites - the tentacular neurite bundle (Figure 12A-insert).

In 24-day-old larvae, the FMRFamide-like immunoreactive nervous system is highly complex and contains numerous thin neurites (Figures 5F, 10H, I, 12B). The most prominent nervous element is the apical organ. It contains monopolar and bipolar or multipolar perikarya (Figure 12C). Monopolar perikarya are triangular with a narrow apical part and a wide basal part; the latter produces one basal process that extends into the neuropil. As before, the bipolar or multipolar perikarya form two dorso-lateral groups that contain between three and seven perikarya (Figure 12C). The dorsolateral parts of the tentacular neurite bundle arise from the dorsal groups of the bipolar or multipolar perikarya of the apical organ. The tentacular neurite bundle passes along the tentacular ridge (Figure 10I). On the dorsal side, the tentacular neurite bundle contains upper and lower branches (Figure 10I). On the median line of the preoral lobe, the median neurite bundle appears (Figure 10J). It contains several neurites and perikarya. The latter are concentrated in the central part of the median neurite bundle (Figure 12D). Radial and circular neurites and two marginal neurite bundles innervate the preoral lobe. Both marginal neurite bundles split into numerous thin neurites where the preoral lobe merges with the hyposphere. The anterior marginal neurite bundle continues into ventro-lateral neurites of the oral field, whereas the posterior marginal neurite bundle passes into the lateral neurites of the oral field (Figure 10I). Thus, there are two pairs of groups of neurites that pass from the preoral lobe to the tentacular neurite bundle and that innervate the lateral and ventro-lateral sides of the oral field. The ventral side of the oral field is innervated by the paired ventral neurite bundle, which contains 15-17 bipolar perikarya (Figure 12E). Some of these perikarya are paired, but commissures are not present. The ventral neurite bundles connect to the oral ring. The latter is very complex and contains numerous neurites and perikarya. The neurites spread along the esophagus and form the cylindrical nerve net with a long dorsal side and a short ventral side (Figure 10H). There are six large perikarya on the dorsal side of the esophagus, whereby three are situated on the dorsal wall of the cardiac sphincter (Figure 10K). At this stage, there are two large perikarya, which are located in the epidermis of the oral field near the mouth (Figure 10I, K). These FMRFamide-reactive perikarya form two or three processes, some of which are in contact with the oral nerve ring (Figure 10K; see also [23]). The number of perikarya in the midgut increases to as many as 8-10 (Figure 12F). They form a circle around the midgut near the pyloric sphincter. The telotroch is innervated by the nerve ring, which passes along its external perimeter (Figure 10I). The trunk and dorsal body region are innervated by thin neurites (Figure 10I). 


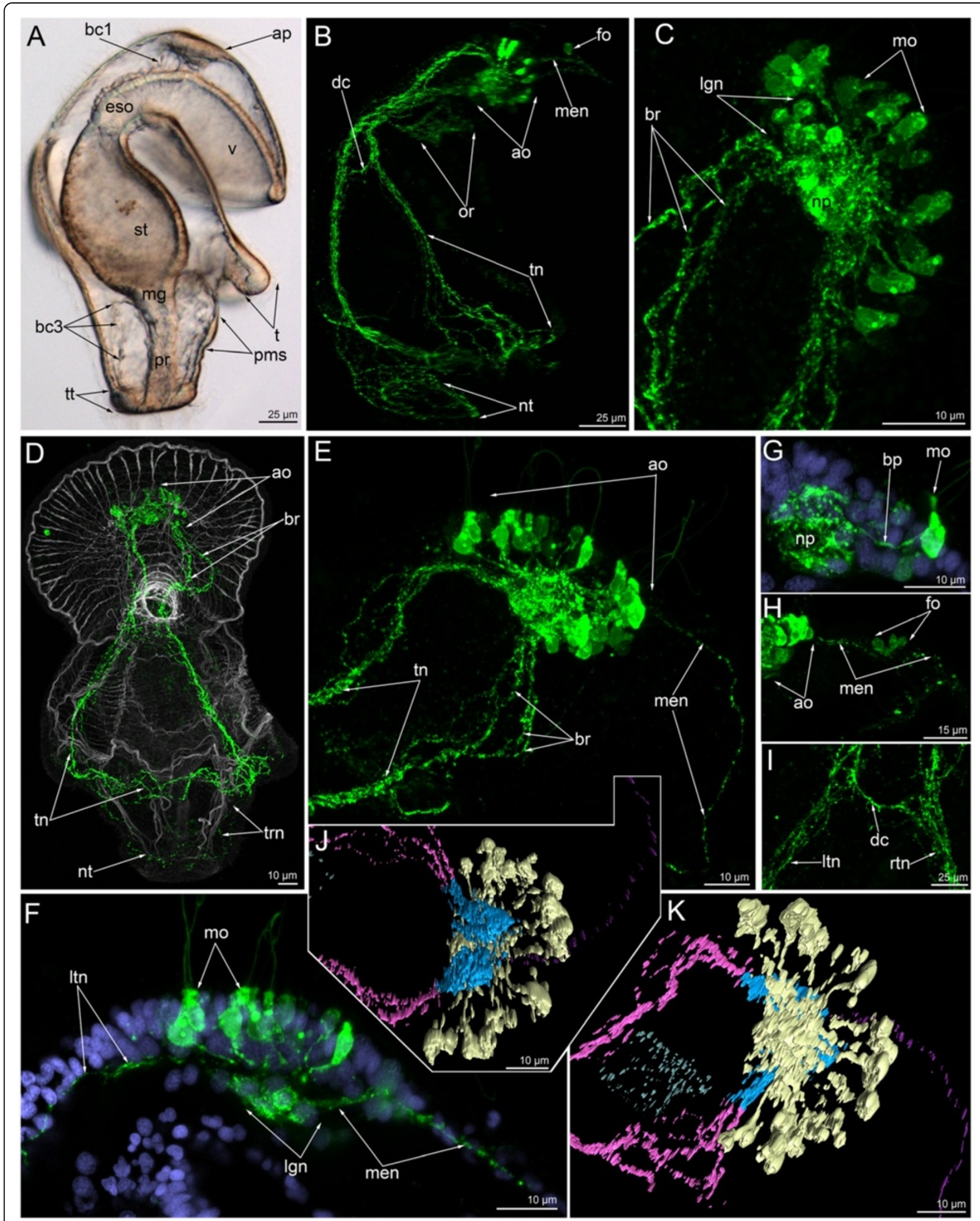

Figure 8 (See legend on next page.) 


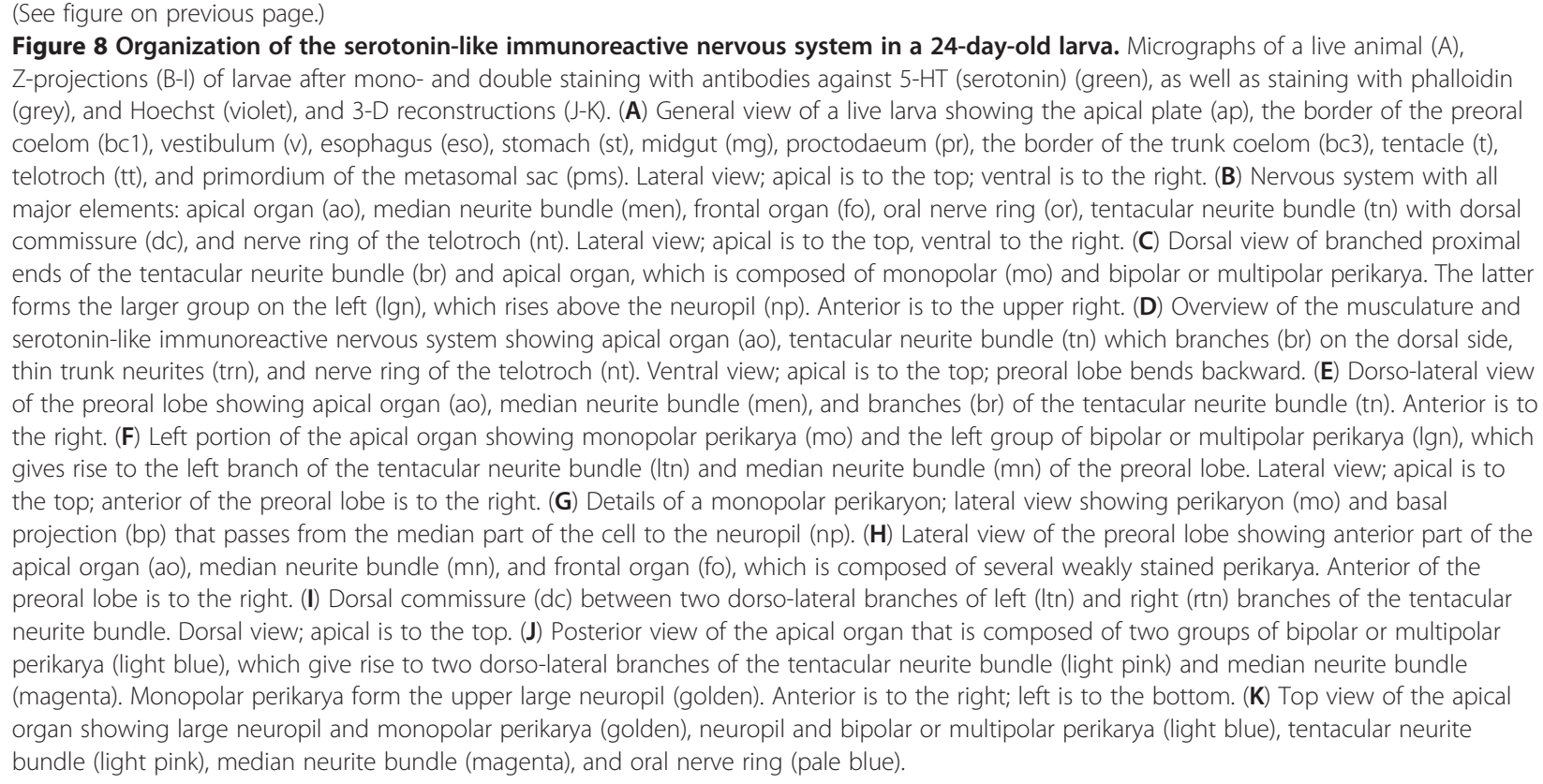

\section{Discussion}

The structure of the larval apical organ in

\section{lophotrochozoans and deuterostomes}

The phoronid larval nervous system was first described on the basis of immunocytochemistry by Hay-Schmidt [16], who analyzed individual stages of early embryos and young larvae of Phoronis vancouverensis. According to these and our data, the first perikarya appear in the apical plate. The differentiation of the first perikarya in the apical organ is a common feature for numerous but not all - lophotrochozoans ([24-27]; but see [28-30]). As is the case in other lophotrochozoans, the initial serotonin-like immunoreactive perikarya in the apical organ are flask-shaped in phoronid embryos. They possess a thin basal process and are retained during the entire larval development. The organization of the apical organ becomes more complex with age, as is indicated by the dramatic increase in the number of cells that constitute the apical organ.

In Phoronopsis harmeri larvae, four types of perikarya form the apical organ: monopolar and bipolar (or multipolar) serotonin-like immunoreactive as well as monopolar and bipolar (or multipolar) FMRFamide-like immunoreactive. Within the apical organ, only the monopolar serotonin-like immunoreactive perikarya are flask-shaped. In young larva, there are 20-25 monopolar serotonin-like immunoreactive perikarya, which form a horseshoe-shaped (U-shaped) field with two dorsal branches. These cells are monociliated, flask-shaped, and their basal processes pass to the centre of the apical organ and form the neuropil. Bipolar (or multipolar) serotonin-like immunoreactive perikarya and some of their processes form the posterior-most layer of the apical organ. Their perikarya form two (left and right) groups with 5-7 perikarya, which are located directly under the monopolar perikarya. In 24-day-old larva, the neuropil, which is composed of the neurites of the bipolar (or multipolar) serotonin-like immunoreactive perikarya, is subdivided into two portions (left and right). The monopolar FMRFamide-like immunoreactive perikarya form one group each on the left and right side of the apical organ, respectively. Bipolar or multipolar FMRFamide-like immunoreactive perikarya are strongly stained and form two dorso-lateral groups, which occupy the most dorsal area of the apical organ. Groups of bipolar or multipolar FMRFamide-like immunoreactive perikarya connect to the tentacular FMRFamide-like immunoreactive neurite bundle and appear earlier than monopolar FMRFamide-like immunoreactive perikarya.

Hay-Schmidt [17] found three types of perikarya in the apical organ of Phoronis muelleri. These are monopolar and bipolar or multipolar serotonin-like immunoreactive perikarya as well as monopolar FMRFamide-like immunoreactive perikarya. In early larvae of $P$. vancouverensis, the apical organ consists of two types of perikarya: monopolar and bipolar or multipolar serotonin-like immunoreactive cells [16]. Interestingly, the apical organ neither contains monopolar nor bipolar (multipolar) FMRFamidelike immunoreactive cells. In Phoronis pallida, two types of serotonin-like immunoreactive perikarya were found in the apical organ: bipolar ciliate and nonciliate [19].

Taken together, the data available show that the apical organs of phoronid larvae have a much more 
complex architecture than that of other lophotrochozoans. It consists of at least four cell types and contains approximately $30-50$ serotonin-like immunoreactive and $16-20$ FMRFamide-like immunoreactive perikarya. The majority of the serotonin-like immunoreactive cells consist of monopolar or (presumably) bipolar flask-shaped perikarya, which form a U-shaped mass.

In most lophophotrochozoan larvae, the apical organ consists of only a few serotonin-like immunoreactive flask-shaped cells (annelids: [28-31]; molluscs: [32-34];

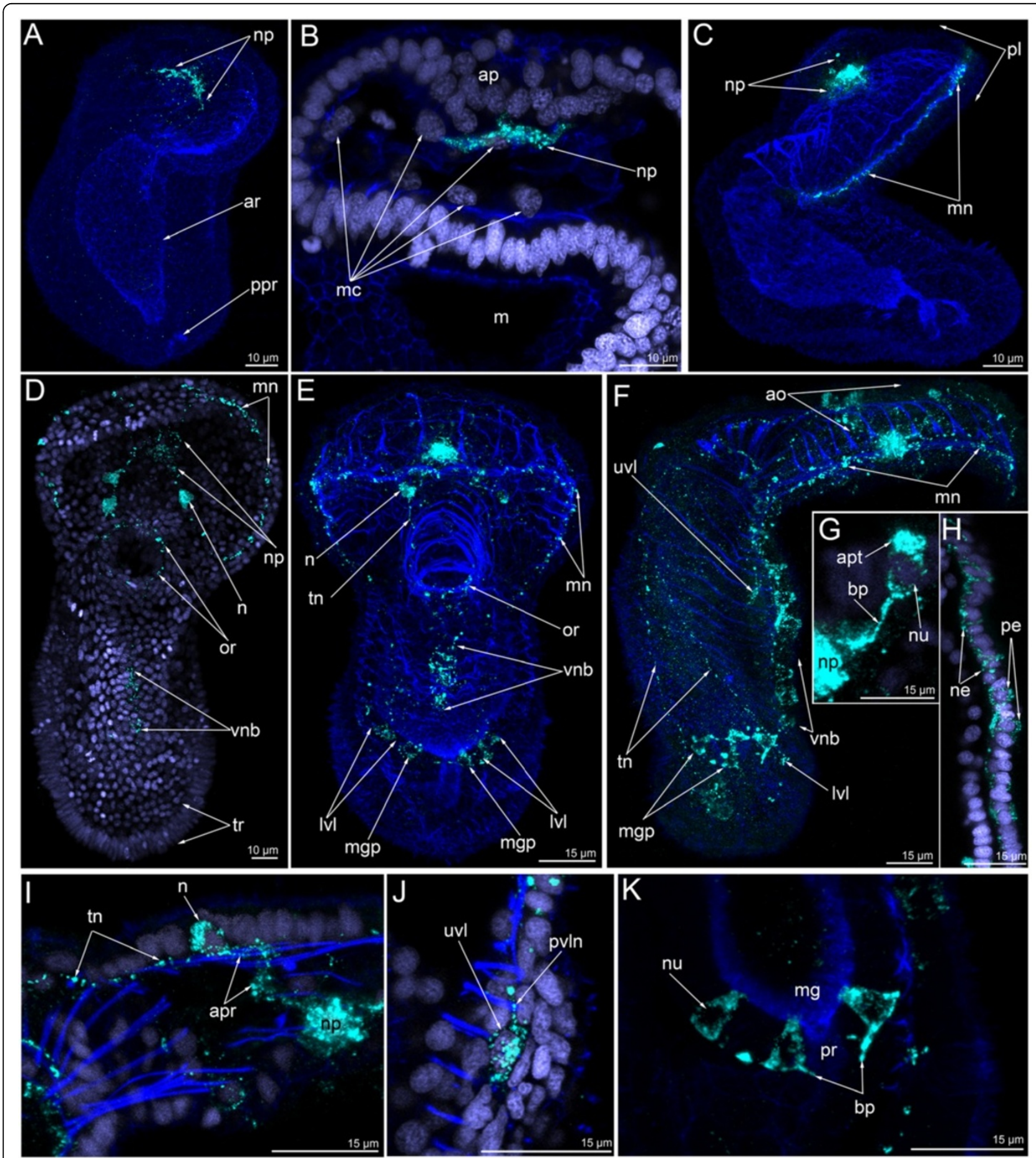

Figure 9 (See legend on next page.) 


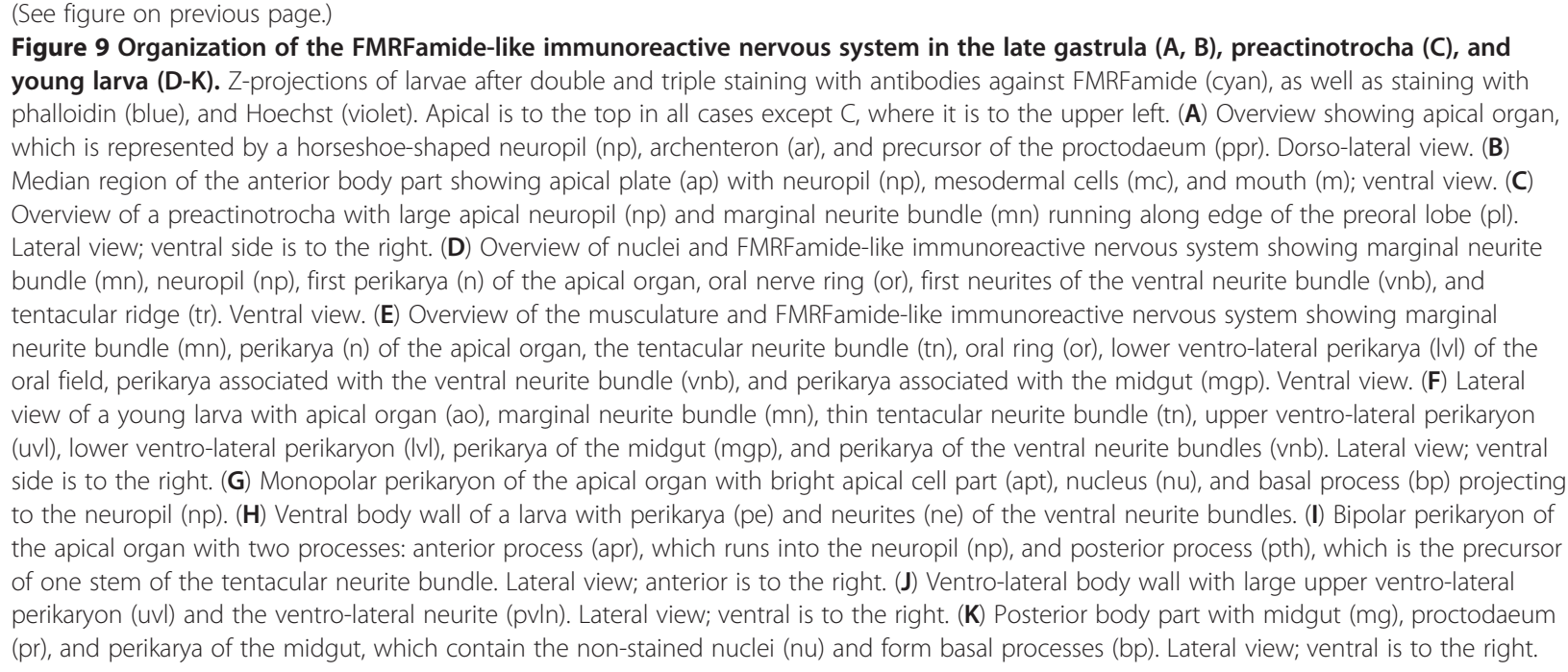

polyclad flatworms: [35]; ectoprocts: [36,37]; brachiopods: [9,38]; see [27] for review). Such a simple apical organ can therefore be regarded as a basal feature of spiralian protostomes [24,27,39]. However, there are deviations from this general pattern. The high degree of complexity of the apical organ of entoproct and polyplacophoran larvae has been considered one of several apomorphies of monophyletic Entoprocta-Mollusca (i.e., Tetraneuralia; [27]). On the other hand, some polychaete annelids or ectoprocts seem to lack flask-shaped cells in the apical organ altogether [40,41].

The organization of the apical organ of lecithotrophic brachiopod larvae differs from that of the swimming planktotrophic juveniles of glottiid brachiopods. While the latter have numerous, probably non-flask-shaped cells, the former have four or more (eight?) serotoninlike immunoreactive flask-shaped cells [9,38,42], again suggesting that these cells belong to the groundpattern of Lophotrochozoa.

In the deuterostome larvae investigated so far (enteropneust tornariae and echinoderm larvae), the apical organ consists of more than ten or fifteen serotonin-like immunoreactive perikarya, the shape of which probably being typically flask-shaped [43-45].

Accordingly, two scenarios concerning the evolution of complexity in invertebrate apical organs appear principally possible. Either, the last common ancestor of protostomes and deuterostomes had a simple apical organ and its complexity evolved three times independently: once in the entoproct-molluscan (tetraneuralian) lineage, once in phoronids, and once in the deuterostomes, or a complex apical organ was present in the last common ancestor and has been retained in the three abovementioned clades, while it was subsequently reduced multiple times independently in the remaining spiralians.
Comparison of the overall neural architecture of phoronid larvae with other lophotrochozoan and deuterostomian larvae

In young $P$. harmeri larvae, the serotonin-like immunoreactive nervous system consists of four perikaryacontaining subsets: the apical organ, a group of six to eight perikarya distributed along the edge of the preoral lobe, frontal organ, and a group containing the oral nerve ring with ventro-lateral perikarya, which connect to the ventral neurite bundles. Perikarya of the preoral lobe interconnect with the serotonin-like immunoreactive marginal neurite bundles of the preoral lobe and can not be recognized in late stages. However, in $P$. muelleri larvae, these perikarya are retained in late stages and are concentrated along the midline of the edge of the preoral lobe (note that the serotonin-like immunoreactive marginal neurite bundle is absent in P. muelleri larvae; [17]).

In older $P$. harmeri larva, a fourth serotonin-like immunoreactive perikaryon appears in the frontal organ. It contains several perikarya which connect to the serotonin-like immunoreactive median neurite bundle of the preoral lobe. The frontal organ has been described for other phoronid larvae as well [46] and contains serotonin-like immunoreactive perikarya [21]. The median neurite bundle of the preoral lobe is found in all phoronid larvae studied so far, except for young stages of $P$. vancouverensis [16]. In the larva of $P$. harmeri, this neurite bundle emerges from the left group of serotonin-like immunoreactive bipolar (or multipolar) perikarya.

$P$. harmeri is the only phoronid larva to date for which a paired ventral neurite bundle has been described ([22], herein). It consists of two longitudinal neurite bundles, each being associated with several bipolar (or multipolar), 
paired perikarya. The ventral neurite bundles are interconnected by serially repeated commissures. Such a ventral nervous system is common for many larval (and/or) adult spiralians, and although the number of the ventral neurite bundles may vary between and even within various phyla, a paired ventral neurite bundle with serially arranged commissures is usually considered basal for lophotrochozoans [27]. Accordingly, the larva of P. harmeri appears to have retained this neural structure, while it was lost in the adults as well as in adults and larvae of the other phoronid species investigated so far. At the same time, the paired ventral neural bundle of $P$. harmeri larvae differs from the one of typical spiralian larvae (for details see [22]).

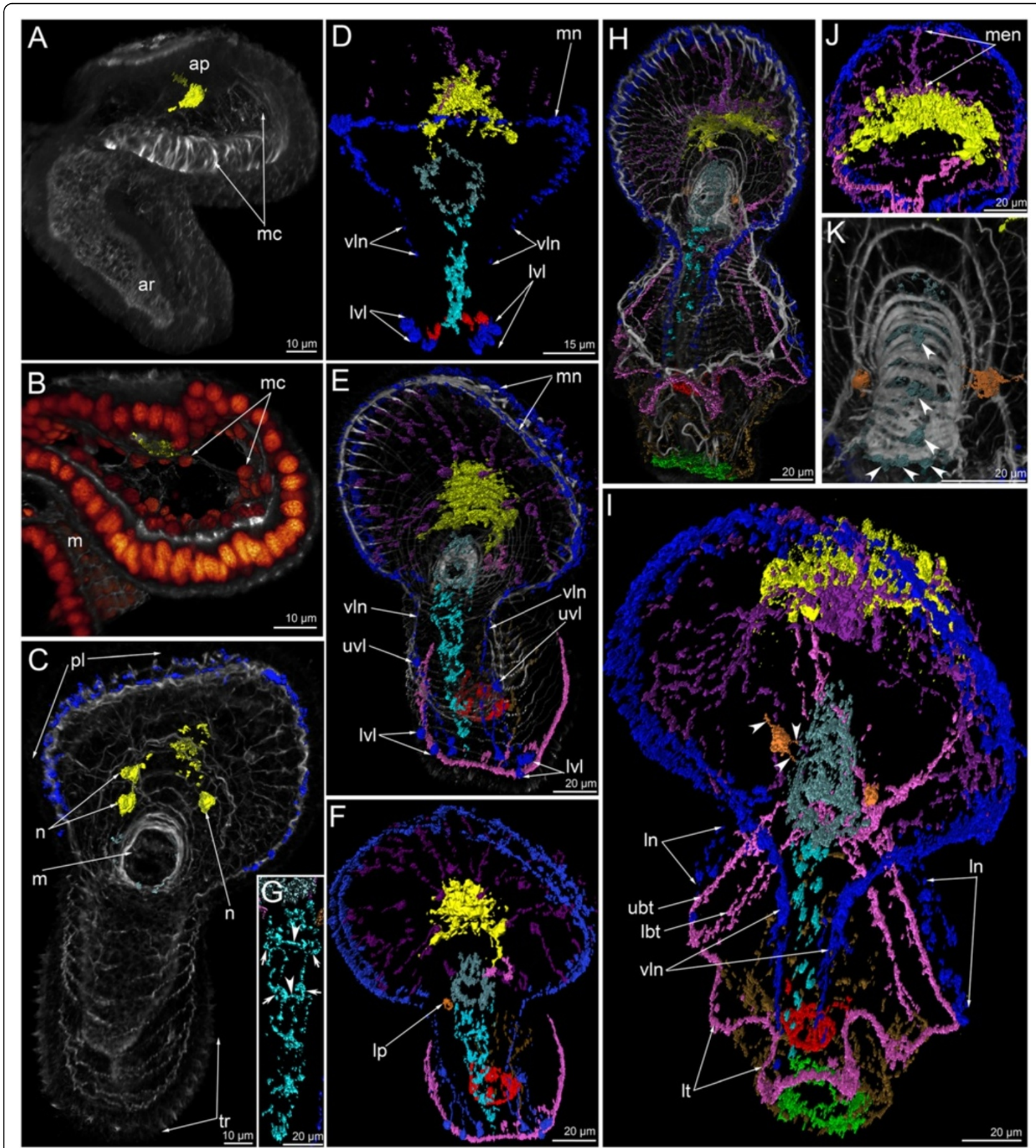

Figure 10 (See legend on next page.) 


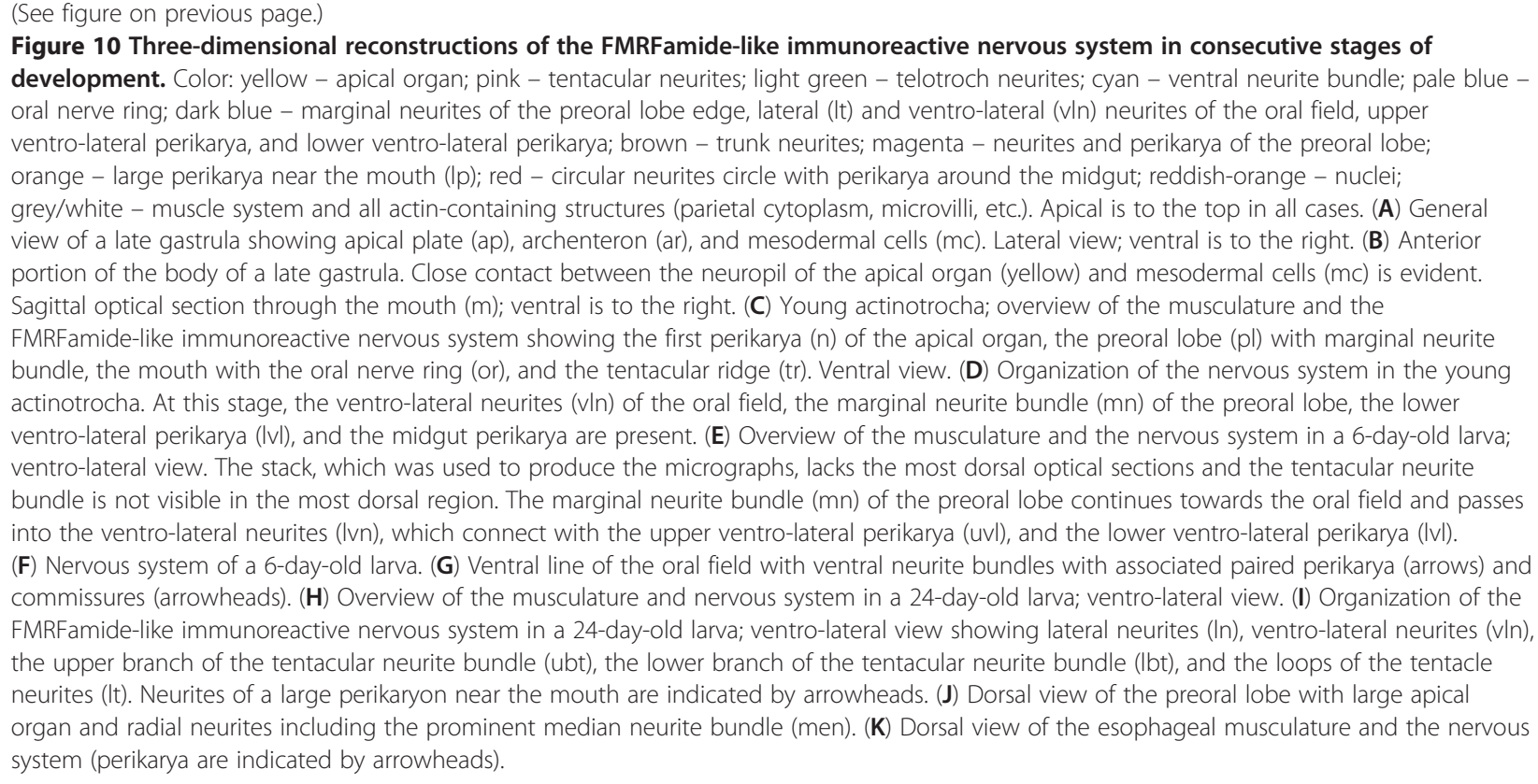

In all phoronid larvae studied to date, the serotoninlike immunoreactive tentacular neurite bundle is a prominent structure. In $P$. harmeri larvae, two dorsolateral branches of the tentacular neurite bundle are connected each other via a dorsal commissure, which seems to be lacking in other phoronid species. According to some data [21], there are two tentacular neurite bundles: one minor (extends along tentacles over them) and one main bundle (extends along tentacles under them).While in phoronid larvae the tentacular neurite bundle forms contact with the apical organ, the apical organ never directly connects to the neurite bundles that innervate the ciliated bands in spiralian trochophores $[25,29,30]$. In ambulacrarian larvae (chinoderms and hemichordates), however, the apical organ is also connected to the neurite bundles of ciliated bands, as is the case in the phoronids [45-48]. Moreover, according to some data $[47,48]$, the apical organ of echinoderms arises as a bilaterally symmetrical nerve plexus, which is generated by neurite bundles of ciliated bands. In ambulacraria, the apical organ arises after or simultaneously with the neurite bundles and perikarya associated with the ciliary bands [44,47], while in actinotroch larvae, serotonin-like immunoreactive neurites innervating the ciliated bands are formed after the establishment of the apical organ. Accordingly, the left and right branches of the apical organ give rise to the two lateral tentacular neurite bundles of the phoronid larva. The telotroch in phoronid larvae is innervated by two (in $P$. harmeri) or one (in $P$. muelleri) serotonin-like immunoreactive circular neurite bundles.
Thus, in all actinotrochs studied, all ciliated bands are innervated by prominent serotonin-like immunoreactive neurite bundles, some of them (e.g., the marginal neurite bundle) containing serotonin-like immunoreactive perikarya. Scattered perikarya associated with neurites that innervate ciliated bands are known from larvae of enteropneust and echinoderm deuterostomes $[44,45,49,50]$.

The larval FMRFamide-like immunoreactive nervous system is very complex in P. harmeri. In this species, the FMRFamide-like immunoreactive nervous system appears to be associated with the major muscle systems. The first neurites appear in the epidermis of the apical plate and then along the edge of the preoral lobe (marginal neurite bundle) in young actinotrochs and is retained in late stages. In older actinotrochs, there are two FMRFamide-like immunoreactive marginal neurite bundles [16,17], herein. These bundles extend into the oral field and furcate into individual neurites, which ventrolaterally connect to two groups of perikarya. In most previous reports $[16,19,21]$, the FMRFamide-like immunoreactive system of actinotrochs does not seem to contain any perikarya even in the apical organ. However, in $P$. harmeri, there are five main groups of perikarya, which are located in the oral field (three groups), the preoral lobe, and the midgut. Perikarya in the oral field were found in P. muelleri larvae. They are multiplied and form the layer along the upper border of the tentacular ring [17]. In larvae of P. harmeri and P. muelleri, there are perikarya along the medio-ventral side of the oral field. In young larvae of P. harmeri, these perikarya are part of the paired ventral neurite bundle. In 
older larvae, the commissures interconnecting the ventral neurite bundles were not found [22]. Another group of perikarya is formed by perikarya which are scattered in the epidermis of the preoral lobe [17], herein. Neurites of these perikarya are associated with the radial muscles of the preoral lobe. Perikarya in the midgut were described for the first time in P. harmeri [23]. The FMRFamide-like immunoreactive tentacular neurite bundle was found in all actinotrochs studied to date $[16,17,19,21]$. It runs under the tentacles and has two

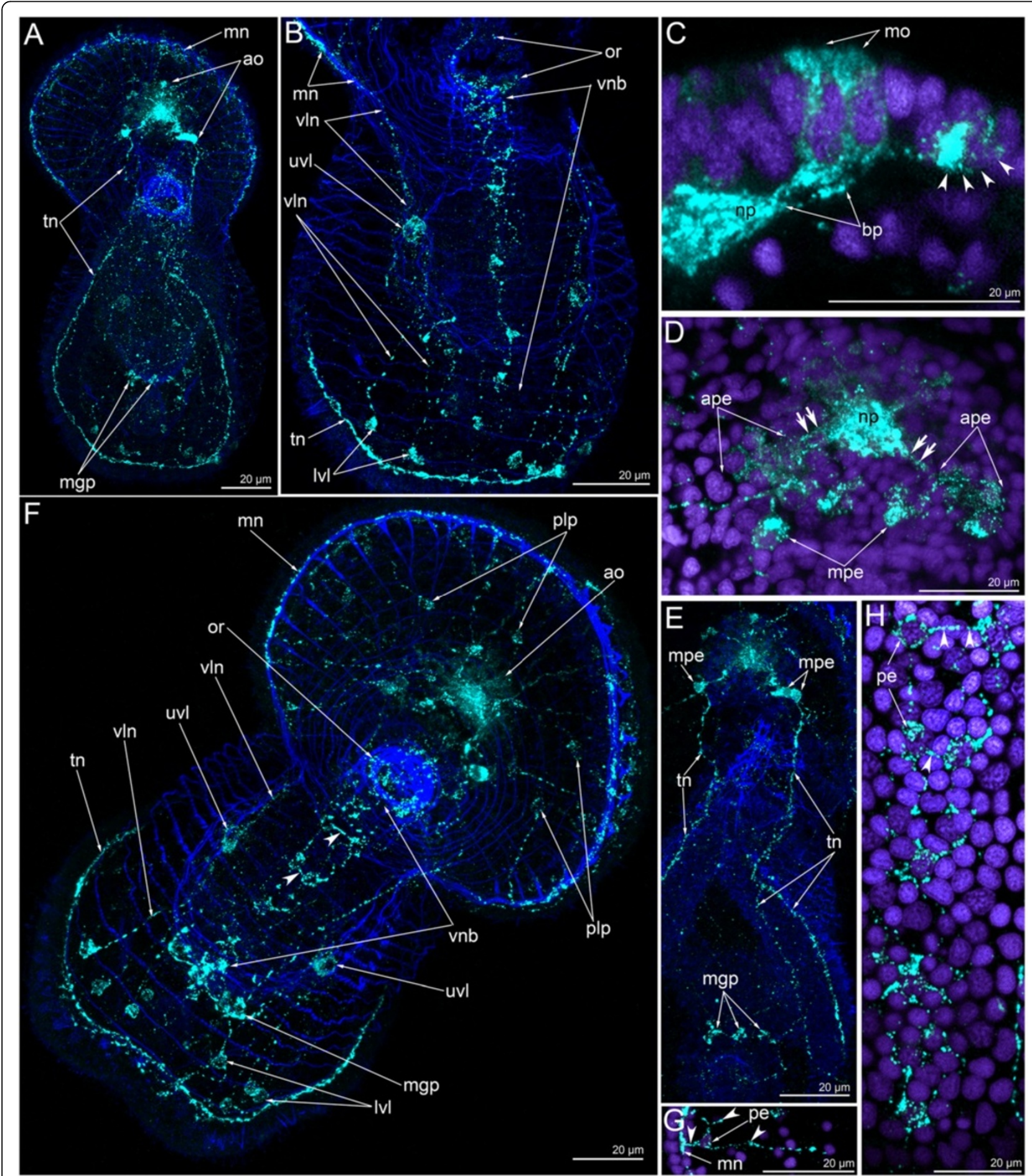

Figure 11 (See legend on next page.) 


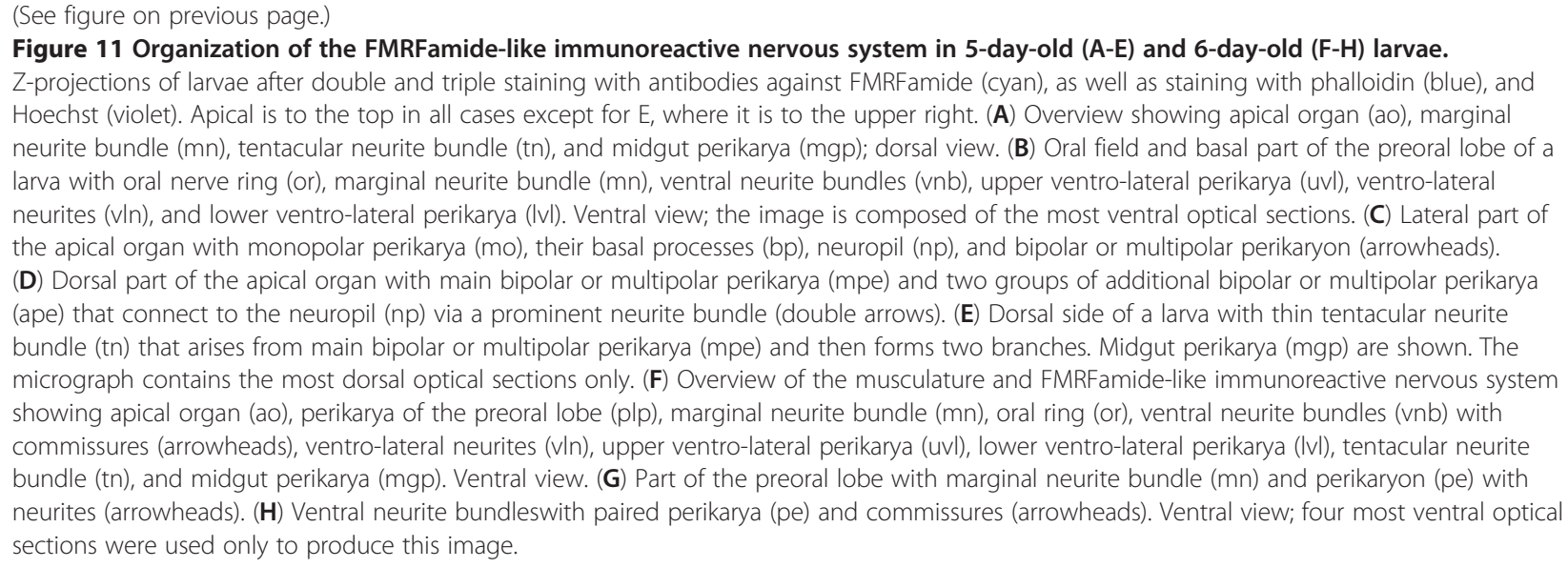

pairs of dorsal branches in $P$. harmeri. The FMRFamidelike immunoreactive nerve ring around the telotroch is described for the first time herein.

The digestive tract of the actinotroch larva is associated with serotonin-like immunoreactive and FMRFamidelike immunoreactive perikarya and neurites (for details see [23]). The most prominent nervous elements were found in the esophagus (oral nerve ring), midgut (FMRFamide-reactive perikarya and circular neurites), and the proctodaeum of actinotroch larvae. Some bilaterian planktotrophic larvae have a nerve ring around the mouth (esophagus), but the innervation of other parts of the digestive tract is still unclear. In trochozoan planktotrophic larvae, there is an oral nerve ring, which connects to apical organ via esophageal connectives [25,28-30]. Some deuterostome larvae have serotoninlike immunoreactive, FMRFamide-like immunoreactive, and SALFamidergic perikarya and neurites in the esophagus, stomach, and pylorus [43,45]. These prominent neural features are directly correlated with the long planktotrophic life in the water column of these organisms.

\section{Conclusion}

P. harmeri has the most complex larval serotin- and FMRFamide-like immunoreactive nervous systems of all phoronids studied to date. The gross anatomy of the nervous system of the actinotroch larva combines characteristics of both lophotrochozoan and deuterostome larvae. On the one hand, the phoronid apical organ consists of flask-shaped serotonin-like immunoreactive monopolar perykaria, which most likely constitute a lophotrochozoan apomorphy [9]. On the other hand, the complexity of the phoronid apical organ, which contains more than 40 serotonin-like immunoreactive perikaria, resembles that of some deuterostome larvae. The distant relationship of phoronids and deuterostomes suggests independent origin of these complex apical organs, although a complex apical organ at the base of the protostome-deuterostome split with subsequent independent simplification in most spiralians cannot be ruled out. The finding of a paired ventral neurite bundle with serially arranged commissures suggests that such a neural feature was part of the ancestral phoronid - and most likely also the ancestral lophotrochozoan - bodyplan, which was secondarily lost in adult phoronids, probably in connection with the acquired sedentary lifestyle.

\section{Methods}

\section{Animals}

Adult Phoronopsis harmeri were collected from May to June 2010 in Coos Bay, Oregon, USA, from intertidal sandy sediments. Fertilized eggs, which were extracted from reproductive females by opening the trunk, were kept in glass beakers containing filtered sea water; the temperature of the egg suspension was maintained at $13-14^{\circ} \mathrm{C}$ by keeping the beaker partially submerged in running sea water on a laboratory bench. Under these conditions, embryos developed normally. Within $15 \mathrm{~min}$ of exposure to sea water, two polar bodies were formed and cleavage commenced. Stages of development were monitored with a stereo microscope. The apical tuft and large apical plate became visible $16 \mathrm{~h}$ after formation of the polar bodies. This stage was determined as the initiation of neurogenesis. Larval cultures had a density of two larvae per 3-4 ml filtered sea water. Larvae were fed mixtures of Rhodomonas lens and Chaetoceros calcitrans and $75 \%$ of the sea water was changed every 2 days. Consecutive stages from the 16-h-old coeloblastula to the 6-tentacled larvae (24 days old) were photographed from living specimens with a Leica DFC 400 camera 


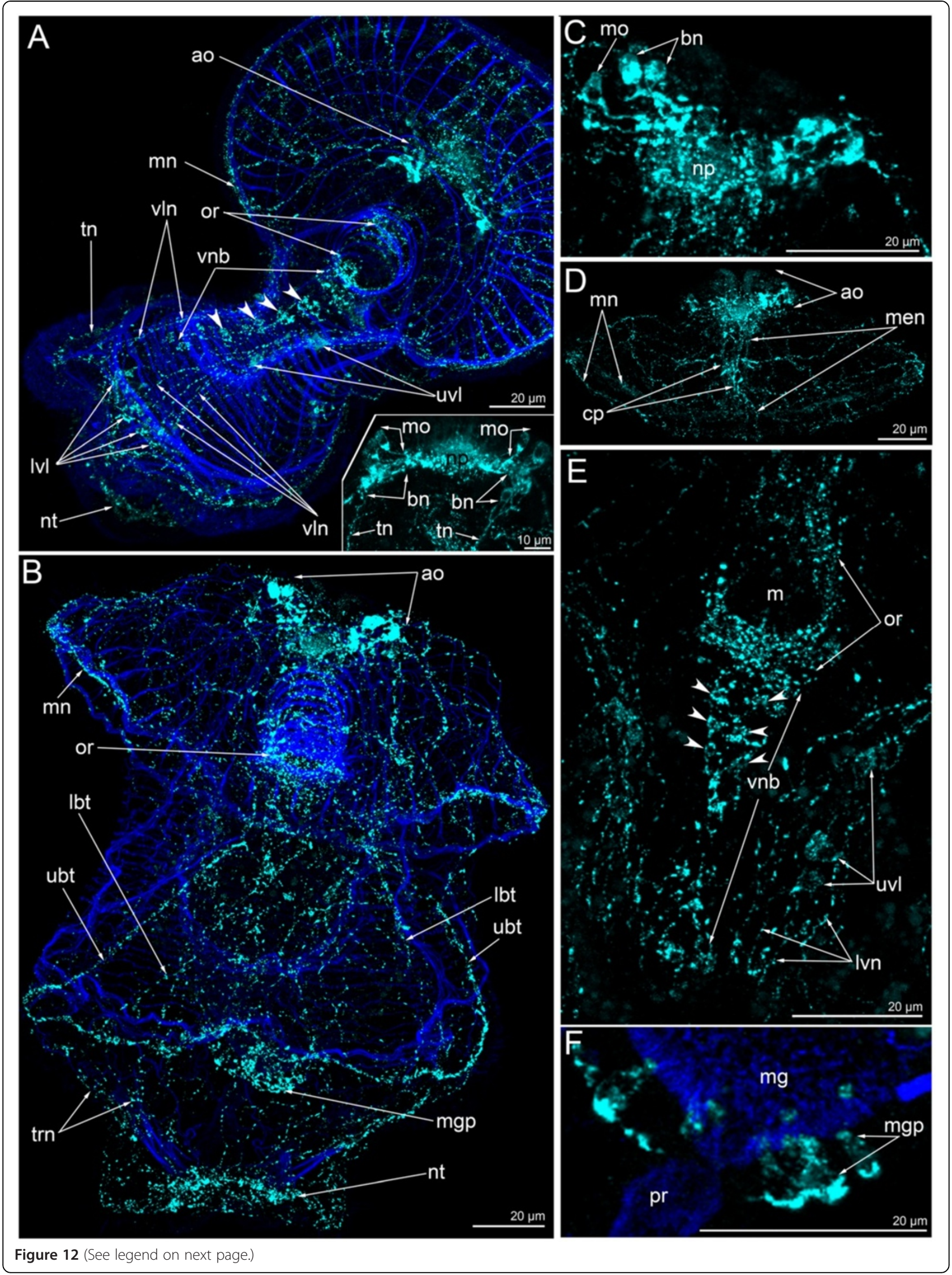




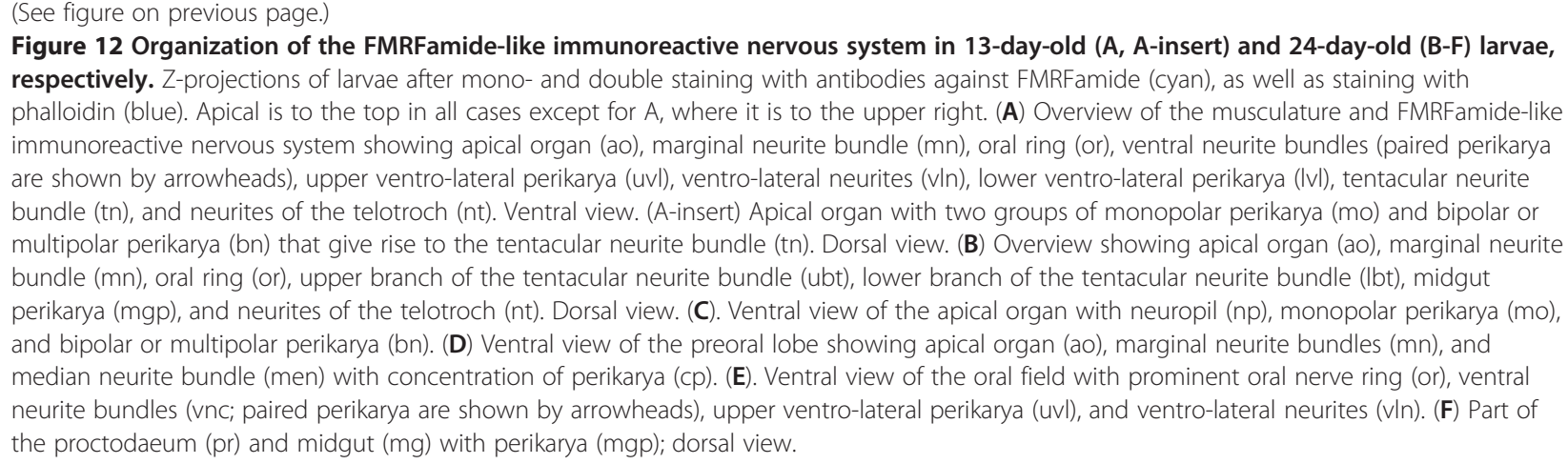

mounted on an Olympus BX51 microscope equipped with DIC optics.

\section{Immunocytochemistry}

At $4 \mathrm{~h}$ intervals (up to the early actinotrocha), specimens were prepared for immunocytochemistry and confocal laserscanning microscopy (CLSM). Embryos and larvae were narcotised in $0.34 \mathrm{M} \mathrm{MgCl}_{2}$ (Fisher Scientific, Pittsburgh, PA, USA), fixed for $60 \mathrm{~min}$ in a $4 \%$ paraformaldehyde (Electron Microscopy Science, Hatfield, PA, USA) solution in filtered sea water, and washed (three times x $15 \mathrm{~min}$ ) in phosphate buffer (pH 7.4) (Fisher Scientific) with Triton X-100 (0.1\%) (Fisher Scientific, Pittsburgh, PA, USA) and 0.1\% albumine bovine (PBT/BSA) (Sigma-Aldrich, St. Louis, MO, USA). Nonspecific binding sites were blocked with 5\% normal donkey serum (Jackson ImmunoResearch, Newmarket, Suffolk, UK) in PBT/BSA for $2 \mathrm{~h}$ at room temperature (RT). Subsequently, the specimens were washed in PBT/BSA, the larvae were transferred into primary antibody (either rabbit anti-serotonin or rabbit anti-FMRFamide, ImmunoStar, Hudson, WI, USA) solutions 1:800 in PBT/BSA and incubated overnight at $4{ }^{\circ} \mathrm{C}$. Specimens were washed (three times $\mathrm{x} 15 \mathrm{~min}$ ) in $\mathrm{PBT} / \mathrm{BSA}$ and then exposed to the secondary antibody, donkey anti-rabbit-Alexa Fluor 488 (Invitrogen, Grand Island, NY, USA), at a dilution of 1:1000 for $2 \mathrm{~h}$ at RT in the dark. Then, the specimens were washed in PBT/BSA and incubated in a mixture of rhodamine-conjugated phalloidin (1:50) (Fisher Scientific, Pittsburgh, PA, USA) and Hoechst (1:1000) (Fisher Scientific, Pittsburgh, PA, USA) for $1 \mathrm{~h}$ at RT in the dark. In the following, they were washed in PBS (three times $x 15 \mathrm{~min}$ ), mounted on a cover glass covered with poly-L-lysine (Sigma-Aldrich, St. Louis, MO, USA), and embedded in Murray Clear or Vectashield (Vector Laboratories Inc., Burlingame, CA, USA). Specimens were viewed with an Olympus confocal microscope (OIMB, OR, USA). Z-projections were generated using the programme Image J version 1.43. Three-dimensional reconstructions were generated using Amira version 5.2.2 software (Bitplane, Zurich, Switzerland).

Since the larval intestine shows strong background signal, it may produce fluorescence on different channels, and some of our micrographs contain nonspecific staining of the intestine. We therefore conducted two experiments to discern autofluorescence of the intestine from true immunocytochemical signal. We treated the larvae according to the protocol described above but omitted either the primary or the secondary antibodies. In both cases, we detected autofluorescence of the intestine on 488, 594 and 633 channels; the samples were devoid of any other signal, however (data not shown).

\section{Competing interests}

The authors declare that they have no competing interests.

\section{Authors' contributions}

ET designed and coordinated research, performed research, analyzed data, and prepared all figures. AW contributed to interpretation and discussion of the data. ET and AW wrote the manuscript. All authors conceived the study, read, and approved the final version of the manuscript.

\section{Acknowledgements}

This research was supported in part by grants to ET from the Russian Foundation for Basic Research (\# 11-04-00690), the Russian Ministry of Education and Science (\#P727, \# 02.740.11.0875), and Grant of the President of Russia (\# MD-2892.2011.4). ET is very grateful to her fiend Svetlana Maslakova for hosting her at the Oregon Institute of Marine Biology in 2010 and for providing resources and training, especially in immunohistochemistry and confocal microscopy. ET is grateful to Thomas Schwaha and Stephan Handschuh for helping her with the Amira program. We thank B. Jaffee for help with the English language.

\section{Author details}

${ }^{1}$ Department of Invertebrate Zoology, Biological faculty, Moscow State University, Moscow 119991, Russia. ${ }^{2}$ Dept. of Integrative Zoology, University of Vienna, Althanstr 14, 1090, Vienna, Austria.

Received: 21 February 2012 Accepted: 6 June 2012

Published: 24 July 2012

\section{References}

1. Cohen B, Weydmann A: Molecular evidence that phoronids are a subtaxon of brachiopods (Brachiopoda: Phoronata) and that genetic divergence of metazoan phyla began long before the early Cambrian. Organisms Divers Evol 2005, 5:253-273. 
2. Santagata S, Cohen B: Phoronid phylogenetics (Brachiopoda; Phoronata): evidence from morphological cladistics, small and large subunit rDNA sequences, and mitochondrial cox1. Zool J Linn Soc 2009, 157:34-50.

3. Halanych KM, Bacheller JD, Aguinaldo AM, Liva SM, Hillis DM, Lake JA: Evidence from $18 \mathrm{~S}$ ribosomal DNA that the lophophorates are protostome animals. Science 1995, 267:1641-1643.

4. Dunn CW, Hejnol A, Matus DQ, Pang K, Browne WE, Smith SA, Seaver E, Rouse GW, Obst M, Edgecombe GD, Sørensen MV, Haddock ShD, SchmidtRhaesa A, Okusu A, Kristensen RM, Wheeler WC, Martindale MQ, Giribet G: Broad phylogenomic sampling improves resolution of the animal tree of life. Nature 2008, 452:745-749.

5. Hejnol A, Obst M, Stamatakis A, Ott M, Rouse GW, Edgecombe GD, Martinez P, Baguñà J, Bailly X, Jondelius U, Wiens M, Müller WEG, Seaver E, Wheeler WC, Martindale MQ, Giribet G, Dunn CW: Assessing the root of bilaterian animals with scalable phylogenomic methods. Proc Biol Sci 2009, 276:4261-4270.

6. Hyman LH: Phoronida. In The invertebrates. Volume 5. Smaller coelomate groups. Edited by Boell EJ. New York: McGraw-Hill; 1959:228-274.

7. Siewing R: Das Archicoelomatenkonzept. Zool Jahrb Anat Ontog 1980, 103:439-482.

8. Temereva EN, Malakhov W: Embryogenesis in phoronids. Invert Zool 2012, 9(1):1-39.

9. Altenburger A, Wanninger A: Neuromuscular development in Novocrania anomala: evidence for the presence of serotonin and a spiralian-like apical organ in lecithotrophic brachiopod larvae. Evol Dev 2010, 12(1):16-24.

10. Temereva EN, Malakhov W: Embryogenesis and larval development of Phoronopsis harmeri Pixell, 1912 (Phoronida): dual origin of the coelomic mesoderm. Invert Reprod Dev 2007, 50:57-66.

11. Temereva EN, Malakhov W: Organization of the epistome in Phoronopsis harmeri (Phoronida) and consideration of the coelomic organization in Phoronida. Zoomorphol 2011, 130:121-134.

12. Nielsen C: Animal phylogeny in the light of the trochaea theory. Biol J Linn Soc 1985, 25:243-299.

13. Nielsen C: Trochophora larvae: cell-lineages, ciliary bands and body regions. 2. Other groups and general discussion. J Exp Zool (Mol Dev Evol) 2005, 304B:401-447.

14. Harzsch S: Neurophylogeny: architecture of the nervous system and a fresh view on arthropod phyologeny. Integr Comp Biol 2006, 46:162-195.

15. Hay-Schmidt A: The nervous system of the actinotroch larva of Phoronis muelleri (Phoronida). Zoomorphol 1989, 108:333-351.

16. Hay-Schmidt A: Distribution of catecholamine containing, serotonin-like and neuropeptide FMRFamide-like immunoreactive neurons and processes in the nervous system of the actinotroch larva of Phoronis muelleri (Phoronida). Cell Tiss Res 1990, 259:105-118.

17. Hay-Schmidt A: Catecholamine-containing, serotonin-lake and FMRFamide-like immunoreactive neurons and processes in the nervous system of the early actinotroch larva of Phoronis vancouverensis (Phoronida): distribution and development. Can J Zool 1990, 68(7):1525-1536.

18. Lacalli TC: Structure and organization of the nervous system in the actinotroch larva of Phoronis vancouverensis. Phil Trans Roy Soc L 1990, 327:655-685.

19. Santagata S: Structure and metamorphic remodeling of the larval nervous system and musculature of Phoronis pallida (Phoronida). Evol Dev 2002, 4:28-42.

20. Santagata S: Larval development of Phoronis pallida (Phoronida): implications for morphological convergence and divergence among larval body plans. J Morphol 2004, 259:347-358.

21. Santagata S, Zimmer RL: Comparison of the neuromuscular system among actinotroch larvae: systematic and evolutionary implication. Evol Dev 2002, 4:43-54

22. Temereva EN: Ventral nerve cord in Phoronopsis harmeri larvae. J Exp Zool (Mol Dev Evol) 2012, 318B:26-34.

23. Temereva EN: The digestive tract of actinotroch larvae (Lophotrochozoa, Phoronida): anatomy, ultrastructure, innervations, and some observations of metamorphosis. Can J Zool 2010, 88(2):1149-1168.

24. Hay-Schmidt A: The evolution of the serotonergic nervous system. Proc $R$ Soc L 2000, 267:1071-1079.

25. Voronezhskaya EE, Tyurin SA, Nezlin LP: Neuronal development in larval chiton Ischnochiton hakodadensis(Mollusca: Polyplacophora). J Comp Neurol 2002, 444:25-38.
26. Wanninger A: Comparative lophotrochozoan neurogenesis and larval neuroanatomy: recent advances from previously neglected taxa. Acta Biol Hung 2008, 59:(Suppl)127-136.

27. Wanninger A: Shaping the things to come: ontogeny of lophotrochozoan neuromuscular systems and the tetraneuralia concept. Biol Bull 2009, 216:293-306.

28. Voronezhskaya EE, Tsitrin EB, Nezlin LP: Neuronal development in larval Polychaete Phyllodoce maculate (Phyllodocidae). J Comp Neurol 2003, 455:299-309.

29. McDougall C, Chen W-Ch, Shimeld SM, Ferrier Dek: The development of the larval nervous system, musculature and ciliary bands of Pomatoceros lamarckii (Annelida): heterochrony in polychaetes. Front Zool 2006, 3(16). doi:10.1186/1742-9994-3-16.

30. Nezlin LP: The golden age of comparative morphology: laser scanning microscopy and neurogenesis in trochophore animals. Russ J Dev Biol 2010, 41(6):381-390.

31. Hay-Schmidt A: The larval nervous system of Polygordius lacteus Scheinder 1868 (Polygordiidae, Polychaeta): immunocytochemical data. Acta Zool 1995, 76:121-140.

32. Dickinson AJG, Croll RP: Development of the larval nervous system of the gastropod Ilyanassa obsoleta. J Comp Neurol 2003, 466:197-218.

33. Voronezhskaya EE, Nezlin LP, Odintsova NA: Neuronal development in larval mussel Mytilus trossulus (Mollusca: Bivalvia). Zoomorphol 2008, 127:97-110

34. Kristof A, Klussmann-Kolb A: Neuromuscular development of Aeolidiella stephanieae Valdéz, 2005 (Mollusca, Gastropoda, Nudibranchia). Front Zool 2010, 7(5). http://www.frontiersinzoology.com/content/7/1/5.

35. Rawlinson KA: Embryonic and post-embryonic development of the polyclad flatworm Maritigrella crozieri; implications for the evolution of spiralian life history traits. Front Zool 2010, 7(12) http://www.frontiersinzoology.com/content/7/1/12

36. Nielsen C, Worsaae K: Structure and occurrence of cyphonautes larvae (Bryozoa, Ectoprocta). J Morphol 2010, 2010(271):1094-1109.

37. Santagata S: Evolutionary and structural diversification of the larval nervous system among marine bryozoans. Biol Bull 2008, 215:3-23.

38. Santagata S, Resh C, Hejnol A, Martindale MQ, Passamaneck YJ: Development of the larval anterior neurogenic domains of Terebratalia transversa (Brachiopoda) provides insights into the diversification of larval apical organs and the spiralian nervous system. EvoDevo 2012, 3(3). doi:10.1186/2041-9139-3-3.

39. Altenburger A, Wanninger A: Comparative larval myogenesis and adult myoanatomy in the rhynchonelliform (articulate) brachiopods Argyrotheca cordata, A. cistellula, and Terebratalia transversa. Front Zool 2009, 6(3):14.

40. Wanninger A, Koop D, Degnan BM: Immunocytochemistry of the larval nervous system of Triphyllozoon mucronatum (Ectoprocta: Gymnolaemata: Cheilostomata) and its fate during metamorphosis. Zoomorphol 2005, 124:161-170.

41. Brinkmann N, Wanninger A: Larval neurogenesis in Sabellaria alveolata reveals plasticity in polychaete neural patterning. Evol Dev 2008, 10:606-618.

42. Altenburger A, Martinez $P$, Wanninger A: Homeobox gene expression in Brachiopoda: the role of Not and Cdx in bodyplan patterning, neurogenesis, and germ layer specification. Gene Expres Patt 2011, 11:427-436.

43. Beer AJ, Moss C, Thorndyke M: Development of serotonin-like and SALMFamide-like immunoreactivity in the nervous system of the sea urchin Psammechinus miliaris. Biol Bull 2001, 200(3):268-280.

44. Nielsen C, Hay-Schmidt A: Development of the Enteropneust Ptychodera flava: ciliary bands and nervous system. J Morphol 2007, 268:551-570.

45. Nezlin LP, Yushin W: Structure of the nervous system in the tornaria larva of Balanoglossus proterogonius (Hemichordata: Enteropneusta) and its phylogenetic implications. Zoomorphol 2004, 123:1-13.

46. Temereva EN: New data on distribution, morphology and taxonomy of phoronid larvae (Phoronida, Lophophorata). Invert Zool 2009, 6(1):47-64.

47. Byrne M, Nakajima Y, Chee FC, Burke RD: Apical organs in echinoderm larvae: insights into larval evolution in the Ambulacraria. Evol Dev 2007, 9:432-445.

48. Burke RD: Deuterostomy neuroanatome and the body plan paradox. Evol Dev 2011, 13(1):110-115. 
49. Murabe N, Hatoyama H, Hase S, Komatsu MK, Burke RD, Kaneko H, Nakajima Y: Neural architecture of the brachiolaria larva of the starfish, Asterina pectinifera. J Comp Neur 2008, 509:271-282.

50. Dupont S, Thorndyke W, Thorndyke MC, Burke RD: Neural development of the brittlestar Amphiura filiformis. Dev Genes Evol 2009, 219:159-166.

doi:10.1186/1471-2148-12-121

Cite this article as: Temereva and Wanninger: Development of the nervous system in Phoronopsis harmeri (Lophotrochozoa, Phoronida) reveals both deuterostome- and trochozoan-like features. BMC Evolutionary Biology 2012 12:121.

\section{Submit your next manuscript to BioMed Central and take full advantage of:}

- Convenient online submission

- Thorough peer review

- No space constraints or color figure charges

- Immediate publication on acceptance

- Inclusion in PubMed, CAS, Scopus and Google Scholar

- Research which is freely available for redistribution 